\title{
AIDS, VICE, AND PUBLIC POLICY
}

\author{
MARK A.R. KLeiman*
}

I

\section{INTRODUCTION}

Governmental actions with respect to the AIDS epidemic should serve three goals: care of the sick, protection of the interests of the infected, and minimization of the number of new infections. Because the likely consequences of infection are so horrible and so hard to ameliorate, minimizing new infections should rank as the most important of the three goals.

Infection can be prevented by reducing the number of risky acts, by reducing the riskiness of each individual act, or by lowering the proportion of risky acts involving a combination of infected and uninfected individuals. "Risk compensation"- the tendency of individuals to respond to riskreducing changes in the environment by behaving less cautiously-may reduce, or even reverse, the value of policies directed at changing the riskiness of specific acts or the infected/uninfected contact rate. Technical and social innovations which allow potential sexual partners easily to determine their relative status (that is, both infected or uninfected, or one of each) could create substantial benefits for some populations. Thinking about them provides an illuminating example of the complications of AIDS related policies.

All approaches to the AIDS problem are complicated by its connection with socially disapproved forms of pleasure seeking. Where policy touches vice, two sets of strong responses are evoked. One response comes from those who regard vice as inherently bad in ways not limited to its observable results. The other comes from those who oppose state interference in such matters on the principle of individual liberty. The two groups are alike in being unwilling to judge policies solely by their likely foreseeable consequences, and thus in their rejection of "policy analysis" as the right way to resolve policy controversy. If AIDS policy remains caught in a crossfire

Copyright $(\mathcal{C} 1988$ by Law and Contemporary Problems

* Lecturer in Public Policy and Research Fellow in the Program in Criminal Justice Policy and Management at the Kennedy School of Government, Harvard University. Philip Cook, John Platt, Peter Reuter, and Thomas Schelling read an early draft of this article and made helpful comments. David Burmaster and Frederick O'R. Hayes carefully edited and commented on the paper when it was in almost final form. The author benefited greatly from discussions with Susan Bell, Allan Brandt, Harvey Fineberg, Janet Gornick, Douglas Lipton, Michael Stoto, and Richard Zeckhauser. Andrew Michaelson and Jennifer Lowe provided editorial help. Richard Mockler performed exemplary research assistance and checked all the footnotes; the author intends to blame him for any remaining errors. 
between moralists and libertarians, there will be many preventable infections and deaths.

\section{II}

\section{Thinking about the Epidemic}

\section{A. Approaching AIDS as if only AIDS Mattered}

The objectives of policy directly related to AIDS should be care of the ill, protection of the interests of the infected, and prevention of new infections. The ill need treatment, although little is yet available other than comfort and palliation. All, or virtually all, of the AIDS patients will die, many of them in extreme discomfort.' Social policy can make their lives easier with competent and sensitive medical treatment and hospice care, psychological counseling and support, and protection from others' irrational fears; social policy can make their lives harder by denying employment, housing, or health care protection to the infected.

The overwhelming interest of the infected is in not becoming ill. Apparently, a variety of insults to the immune system can speed the process of disease expression. ${ }^{2}$ It is likely that drugs such as azidothymadine (AZT) can retard that process. ${ }^{3}$ The probability that an infected person will become ill remains disputed, but long term cohort studies suggest rates of more than 50 percent. ${ }^{4}$ It is possible that many infected individuals whose immune systems do not collapse will die from degeneration of their central nervous systems. ${ }^{5}$

Infected persons also have more immediate interests in maintaining their employment, their housing, their health insurance, their lifestyles, and their anonymity. However, preventing new infections should take precedence among policy objectives because the consequences of infection are so unpleasant. Of two alternative courses of action, the one which is less effective in reducing the transmission of AIDS ought to have very substantial advantages on other criteria to receive serious consideration.

It is important to develop an overall view of the biomedical, technological, social, and strategic aspects of any AIDS control policy before examining specific policies as they apply to particular groups or situations. This essay will first examine transmission and transmission prevention, interventions and the way individuals can be expected to react to changes in risk, and the technical ramifications and political implications of testing and identification devices. Then, it will apply these general concepts to specific populations and problems.

1. See Institute of Medicine \& National Academy of Sciences, Confronting Aids: Directions for Public Health, Health Care, and Research 47 (1986) [hereinafter N.A.S.].

2. Id. at 45, 56 (for example, infection with pathogens, exposure to foreign proteins, pregnancy).

3. Id. at 215 .

4. Id. at 7; see also German Survey's Gloomy Outlook, 324 Nature 199 (1986).

5. N.A.S., supra note 1 , at 49 (The virus infects nerve cells as well as immune-system cells.). 


\section{B. The Algebra of Transmission}

The AIDS virus, HIV, can encode its genetic information into the nucleus of T4 helper lymphocytes, a variety of what were once called "white blood cells". ${ }^{6}$ In addition to blood, the virus has been isolated from other body fluids, including semen. ${ }^{7}$ The virus can be transmitted when any body fluid from an infected person enters the bloodstream of an uninfected person, or makes contact with the $\mathrm{T} 4$ helper cells in the vagina. ${ }^{8}$ The virus also can be transmitted from mother to child in utero or by breast feeding. ${ }^{9}$ Sexual congress of various kinds, the sharing of hypodermic needles, and transfusions of blood or blood components account for nearly all of the known cases of transmission in the United States. ${ }^{10}$ Persons infected with HIV are commonly referred to as "seropositive" and those not so infected as "seronegative."'1

The chances of becoming infected with HIV depend on what an individual does, how often, and with whom. ${ }^{12}$ An individual's probability of becoming infected within " $n$ " acts of a particular type with partners chosen at random is $1-[1-(R * S P O S)]^{n},{ }^{13}$ where " $R$ " equals the risk of acquiring the virus

\section{Id. at 43 .}

7. Id. at 51 .

8. Id. at 190 .

9. See Letter from LaPointe, Michaud, Pekovic, Chausseau \& Dupuy to New Eng. J. MED., reprinted in 312 NEw ENG. J. MED. 1325, 1325 (1985) (case study suggests transplacental transmission of HTLV-III virus); Zeigler, Cooper, Johnson \& Gold, Postnatal Transmission of AIDS-Associated Retrovirus from Mother to Infant, 1985-1 LANCET 896, 896-97 (case study suggests transmission by breast feeding).

10. N.A.S., supra note 1 , at 50 .

11. This paper follows this nomenclature although it is not entirely accurate.

12. This paper assumes, as most of the literature does, that forms of contact other than sex, needle sharing, and transfusion (often referred to as "casual contact," and including situations where blood or other fluids enter through minor breaks in the skin, as when an infected individual bleeds on an uninfected individual who has a cut, or through insect bites) pose only negligible risks, at least under U.S. conditions. See, e.g., Mueller, The Epidemiology of Human Immunodeficiency Virus, 14 LAw, Med. \& Health Care 250, 256 (1986); Leishman, AIDS and Insects, The Atlantic Monthly, Sept. 1987, at 56. If this were incorrect, far more intrusive policies would be required to control the epidemic. Screening of blood donors and of donated blood has reduced the transmission related risk to near zero. See N.A.S., supra note 1, at 61 .

13. The formula is derived as follows:

The chance of being infected on any one occasion is the specific risk $(R)$ times the chance that one's partner is infected (SPOS). Thus, if there were a $50 \%$ chance that one's partner were infected and a $2 \%$ chance that a given act will lead to transmission, then the probabilities of becoming infected after the first act would be $0.5 \times 0.02=0.01$. Thus, the chance of remaining uninfected after one act is $1-(R \times S P O S)$; in this example, 0.99 . This is the chance of "success" at remaining uninfected in one trial. Remaining uninfected on " $n$ " such occasions (drawing a new partner each time) requires " $n$ " consecutive successes, and, assuming that the chance on each trial is independent of previous results, the multiplication rule provides the basis for computing the chance of remaining uninfected after $\mathrm{n}$ trials. For example, the chance of remaining uninfected after two trials would be $0.99 \times 0.99$ (i.e., $0.99^{2}$ ) or .9801 ; of remaining uninfected after three trials $0.99 \times 0.99 \times 0.99$ (i.e., $0.99^{3}$ ) or 0.9703 , and the chance of remaining infected after " $n$ " trials 0.99 ". The chance of being infected is 1 minus the chance of remaining uninfected; if $1 \%$ are infected, $99 \%$ are not. Thus, the chance of remaining uninfected in " $n$ " trials is $1-[1-(R *$ SPOS $)]$ ". Since few if any persons either choose partners at random or engage in exactly the same behavior repeatedly, a precise determination of risk would require a more elaborate calculation, but the formula as given seems adequate for exposition. 
through a single act of a given type with an infected partner (sometimes called "specific risk"), "SPOS" equals the seroprevalence rate in the population from which partners are drawn, and " $n$ " equals the number of acts. This formula ignores the possibility that per-act risk will increase over time due to a series of exposures to the virus. In such "multiple-hit" models, risks rise more rapidly with " $n$ " than the formula suggests. Applying the formula to estimating what proportion of an at-risk population will be infected assumes further that individuals are homogeneous with respect to their propensities for infection. If that were untrue-in particular, if some persons had natural immunity-the cumulative probability of infection over the population might rise toward some value less than unity.

An individual can improve the safety of his or her conduct by controlling the frequency of his or her risky acts, the riskiness of each act, or the prevalence of the virus among his or her partners. As any one of these three variables approaches zero, so does the individual's probability of becoming infected. The relationships are far from linear. An increase in the number of partners, independent of the number of different acts, increases the risk of infection in two ways. First, it raises the probability of having one or more seropositive partners over a long series of contacts. If partners are randomly selected from a population with a seroprevalence rate "SPOS" over a long series of risky acts, an individual's probability of infection approaches unity (certainty) as the number of acts rises without limit. However, if a single partner is chosen from the same population, the probability of infection rises more slowly and approaches, not unity, but the rate of the infection in the general population. The probability of infection after " $n$ " acts of risk " $R$ " with a single partner with a "SPOS" chance of being infected would be [ $1-[1-(R$ * SPOS) $\left.]^{n}\right]$. Second, if fidelity tends to be mutual, a single chosen partner's probability of being infected rises more slowly in a world of rising prevalence than does the probability of infection for partners chosen at random. 


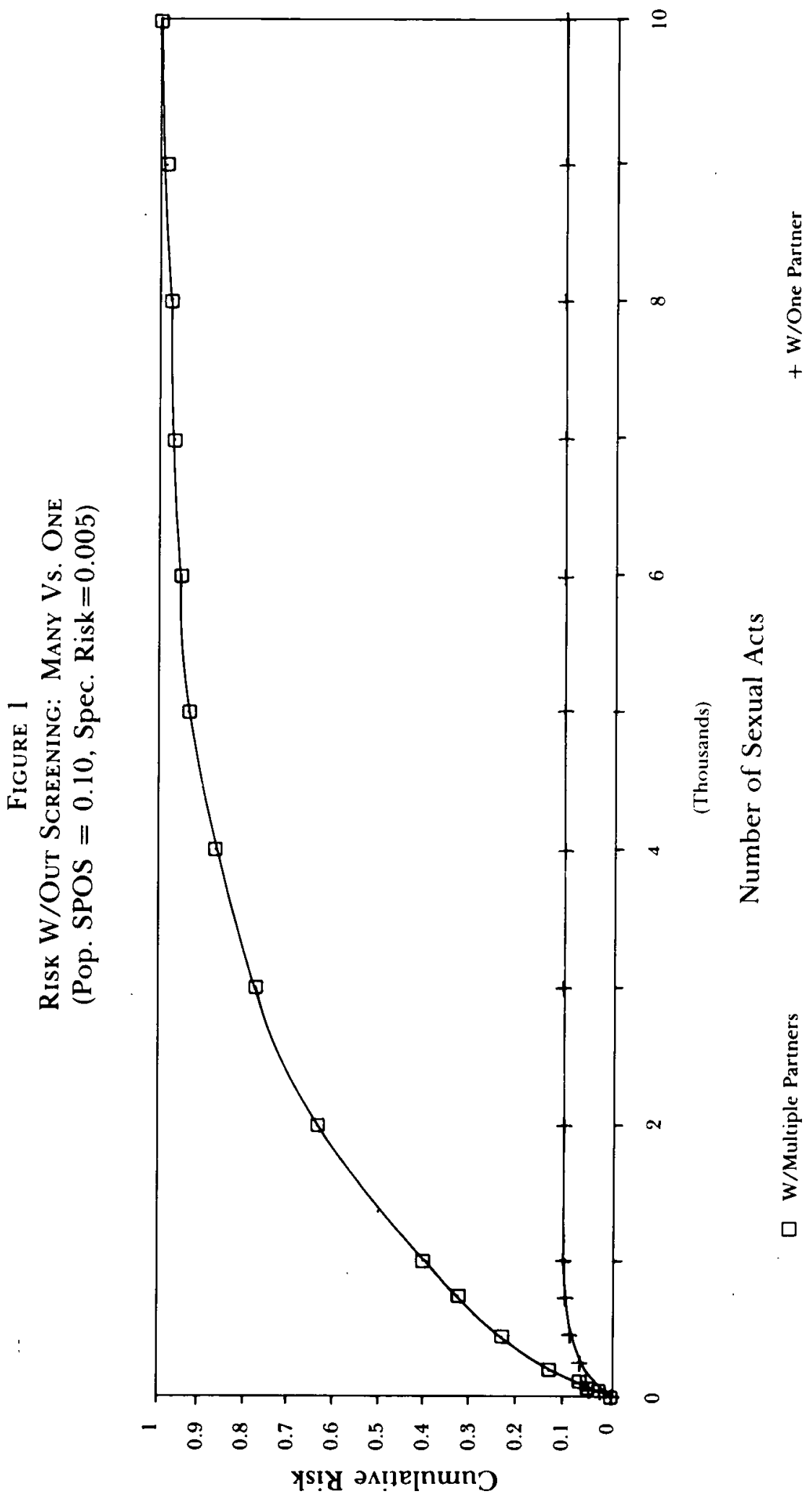




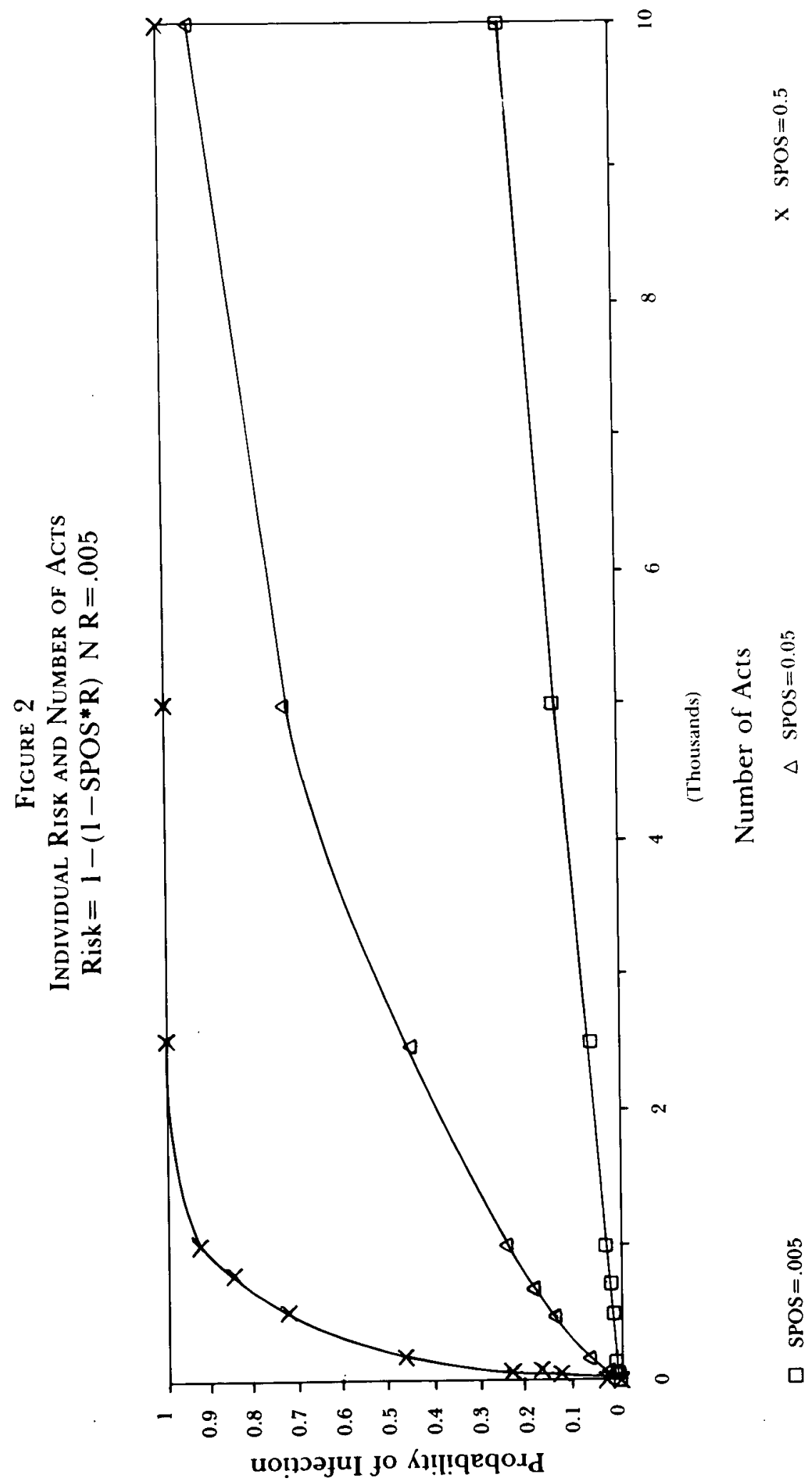


Although an individual may care only about his or her own probability of infection, public concern should focus on the total number of transmissions. The number of transmissions depends upon the number of risky contacts, the specific risks, and the proportion of contacts where one partner is infected and the other is not. Thus, transmissions can be controlled by reducing frequency, reducing specific risks, or reducing the probability that any given contact involves both seropositive and seronegative individuals.

\section{Probabilities of Retransmission Across Populations}

The algebra of transmission becomes much more complicated when the probability of retransmission is taken into account. Each newly infected person has some probability of infecting one or more additional persons, a probability that will vary from person to person. Some individuals, if infected, will be particularly likely to transmit the virus to many partners, while others will present much smaller retransmission risks. In planning interventions, these differences matter; the more likely a person is to retransmit, the more valuable it is to keep him or her from becoming infected in the first place. Similarly, preventing the infection of someone on one occasion whose behavior and setting make it highly probable that he or she will be infected later on is less valuable than preventing the infection of someone who is otherwise at very low risk. ${ }^{14}$

The epidemic control effort faces a number of analytic tasks. Specifying how retransmission and the probability of later infection, if infection is prevented on one occasion, influence the relative value of different interventions stands out among those analytice tasks, both in importance and in conceptual and computational difficulty.

Since the behaviors implicated in becoming infected are largely identical to those implicated in transmitting infection, determining which individuals are most worth protecting from an epidemic-control viewpoint is extraordinarily complex; the two factors-retransmission probability and probability of becoming infected later if "saved" now-act in opposite directions. A comprehensive model has yet to be developed. However, three general remarks can be made.

First, high-transmission-activity individuals in subpopulations with low current prevalence of the virus deserve special attention. If, for example, there were an isolated group of intravenous drug users who shared needles among themselves, and if none of them were currently infected, preventing the first infection would be extraordinarily valuable. Second, as the prevalence among a subpopulation rises, the number of secondary infections prevented by preventing primary infections falls. For example, once half of the hypothetical drug using group's members were infected, preventing one member from being infected on one occasion would not greatly change either

14. Preventing such a transmission would still be valuable, because it would lengthen the period after which the individual becomes infectious, in addition to lengthening his or her life expectancy. 
his lifetime chances of infection or the overall riskiness of sharing needles among the group. Finally, transmission to individuals outside the established "risk groups" deserves special attention. The partners of someone with no obvious infection risk are less likely to protect themselves than those of someone with such risks. Moreover, both the primary and secondary cases are less likely to be infected later when the individuals are outside the established "risk groups."

\section{Risky Acts and Their Specific Risks}

Blood transfusion has the highest specific risk; there is no documented case where a recipient of whole blood from an infected donor did not become infected. No technique is in sight to reduce the specific risk in whole blood transfusion. ${ }^{15}$

Injection with a hypodermic syringe previously used by another person is risky, particularly if that person drew some blood into the syringe. ${ }^{16}$ Needle sharing is unknown in medical practice in the United States, but is common among those who inject illicit drugs. ${ }^{17}$ Under street conditions, any injection must be regarded as risky, because used needles are sometimes repackaged and sold as new. ${ }^{18}$ The specific risk of self-injection can be reduced by sterilizing the needle and syringe. ${ }^{19}$

The risk to the party penetrated (the "receptive" partner) varies in sexual contact involving anal, vaginal, or oral penetration, apparently in that order. ${ }^{20}$ The "insertive" partner is also at a substantial risk under Central African and Haitian conditions where open lesions are common; this risk is much lower under U.S. conditions. Lesions in the skin or mucous membranes, such as those caused by sexually transmitted diseases ("STD's"), seem to increase an individual's specific risk. ${ }^{21}$ To the extent that such lesions promote infection, preventing STD's helps control the specific risk of sexual contact. The use of condoms reduces specific risk directly, by preventing interchange of body fluids, and indirectly, by reducing STD transmission.

\section{E. Strategic Interaction and Transmission Rates}

From the perspective of reducing the total number of new HIV infections, the seropositive and seronegative populations are symmetric; sexual contact

15. N.A.S., supra note 1, at 54 (Although transfusions of some blood factors can be made safe by heating, heating destroys whole blood.).

16. Id. at 6 .

17. Id. (HIV may be transmitted through IV drug use). All such injections are referred to as "intravenous" or "IV" drug use, though some subcutaneous injection occurs.

18. Friedman, DesJarlais \& Sotheran, AIDS Health Education for Intravenous Drug Users, 13 HEALTH EDuc. Q. 383, 387 (1986). The risk is reduced rather than eliminated due to the possibility of faulty sterilization technique.

19. Cf. id. at 386-87 (IV users have attempted to sterilize needles to avoid HIV transmissions).

20. N.A.S., supra note 1, at 51-52. The medical literature is remarkably free of any sort of conjecture on specific risks of different acts; this would seem to be an important area of inquiry so far unexplored.

21. Id. 
of needle sharing within either group poses no threat of infection, but contact across group lines does pose such a threat. To avoid infecting others, seropositives should avoid risky contact with seronegatives; to avoid becoming infected, seronegatives should avoid contact with seropositives. If there is a general moral duty to avoid harming others, seropositives have a moral duty to avoid transmitting the infection. Because any infected person risks infecting others, seronegatives have a moral duty to avoid becoming infected.

To the extent that sex and needle sharing are accompanied by bonds of affection and esteem which lead partners to be concerned about each other's health, individuals will have private reasons to avoid spreading the virus. But some individuals will be more concerned about protecting themselves than they are about protecting their partners, particularly where contact is anonymous, indifferent, or even hostile. In these cases, the symmetry between the infected and the uninfected breaks down; the infected threaten the health of the uninfected, but not vice versa.

Moreover, body fluid contact between seropositive persons, although "safe" as far as new infection is concerned, might increase their risks of progressing from infection to active disease. Because reexposure to HIV may be a cofactor for disease expression, ${ }^{22}$ a rational, but entirely selfish, infected person would prefer an uninfected to an infected sexual partner. ${ }^{23}$ Asymmetric risk creates an incentive to misrepresent one's own HIV status once one is infected. Thus, even if there were no psychological or practical barriers to learning one's HIV status, self-interest alone need not lead to socially optimal behavior.

Even the incentives for the uninfected to avoid infection do not reflect the common interest in their doing so. A rationally selfish, uninfected person would choose, all other things equal, to have sexual relations or share needles with another uninfected individual rather than an infected one. If caution, whether in the form of screening potential partners, reducing sexual frequency, or practicing safer sex, has costs in inconvenience, embarrassment, or pleasure forgone, these costs must be weighed against the benefits of reduced risk. Not all of the benefits accrue to the individual practicing caution because not all of the costs are borne by the newly infected. In addition to further burdening strained health care resources, each new infection presents an increased chance of further infections.

The consequences of infection arguably create more than adequate incentives for caution. But despite the catastrophic consequences of infection, extremely low probability risks may be inadequate deterrents, even if the decisionmaker is perfectly rational. The tendencies some persons have

22. Harris, The AIDS Epidemic: Looking into the 1990's, Technology ReV., Jul. 1987, at 58, 61 (computations from working backward from AIDS data to get the number of individuals infected with HIV).

23. Although exposure to foreign proteins or pathogens may also be cofactors in disease expression, the practice of safe sex and the sterilization of needles might still confer some health benefit on the infected individual. 
to undervalue future costs when weighing them against current benefits only aggravates the problem. ${ }^{24}$ If the average American would value avoiding certain infection at about $\$ 1$ million, a gain worth $\$ 2$ would be adequate to privately justify a one-in-a-million risk. ${ }^{25}$

Then, even with perfect information, perfect calculation, and perfect selfcontrol, purely selfish individuals, whether infected or uninfected, will tend to underinvest in preventing transmission of the virus. ${ }^{26}$ This conclusion justifies public actions to change both preferences and circumstances. There are benefits both to raising the subjective costs of careless behavior ${ }^{27}$ and to lowering the costs of caution. ${ }^{28}$ But few policies to accomplish either goal are free of side effects, uncertainty, or controversy.

\section{F. Interventions, Side Effects, and Risk Compensation}

An almost unlimited variety of actions by public and private agencies might reduce or increase the rate of HIV transmission. It is helpful to ask six questions when evaluating any proposed policy. First, what transmission factor does the proposal intend to reduce: frequency, specific risk, or the rate of contact between the infected and the uninfected? ${ }^{29}$ Second, will the action

24. Zeckhauser, Procedures for Valuing Lives, 23 Public Policy 419, 438, 444-45 (1975).

25. A one-in-a-million risk would arise from, for example, a sex act having a specific risk of onein-a-thousand with a partner drawn from a population with a seroprevalence of one-tenth of $1 \%$.

26. Indeed, perfect information and perfect calculation may not be socially desirable. If, for example, men overestimate their risk of infection in heterosexual intercourse, their behavior may more nearly approach the optimum than it would if they knew how safe they are.

27. The subjective costs of careless behavior could be raised by persuading people that they have duties not to spread infection and not to risk infection.

28. The costs of caution could be reduced by encouraging partner screening, reduced frequency, and safer techniques of sexual congress and self-injection. 1.

29. An unselective list of possible interventions, organized by target risk factor, appears as Table

TABLE I: POTENTIAL INTERVENTIONS TO CONTROL HIV

REDUCING FREQUENCY REDUCING SPECIFIC RISK REDUCING S+/S-CONTRACT

Anti-sex messages

Reduction in pro-sex messages

Anti-drug messages

Drug treatment

Drug enforcement/Compulsory abstinence for ex-convicts Prostitution enforcement

Tighter prison administration (e.g., more surveillance, stricter contraband searches)
Specific messages aimed at safe or safer sex

Increased access to barrier contraception (W/Reduced access to non-barrier contraception?)

STD prevention and treatment

Anti-needle-sharing messages

Education about needle sterilization Needle legalization
(BY REDUCING NUMBER OF PARTNERS)

Close bath houses/sex clubs

Crackdown on shooting galleries

Anti-promiscuity messages

(BY ENCOURAGING ASSORTATIVE MATING BY INFECTION STATUS)

Premarital testing

Testing/identification systems 
taken to reduce one factor cause an increase in another?30 Third, what effects will the knowledge that one risk factor has been reduced have on behavior? ${ }^{31}$ Fourth, what side effects will the proposed intervention have on the health and welfare of the infected and the care of the sick?32 Fifth, what side-effects will the intervention have on situations other than the AIDS epidemic, either directly or through changes in behavior that adjust to decreased risk?33 Finally, what effects will the intervention have on public morals and liberties? ${ }^{34}$

The possibly perverse results that risk reduction can create-results that flow from individuals' knowledge of decreased risk and their use of that knowledge-are discussed in the economics literature under the heading of "risk compensation." 35 In general, everyone responds to the risks he or she faces. Risk is a kind of cost; lower "prices" in the form of lower risks lead to more "consumption."36 Despite cognitive and psychological difficulties in dealing with uncertainty, ${ }^{37}$ caution responds to risk. Generally, if risk diminishes, caution does also. For example, if drivers perceive that passive restraints reduce their risk of injury from collisions, they will drive faster. Thus, imposed measures to reduce risk lead to compensating behavior which tends to increase risk. ${ }^{38}$

Increases in safety devices can even lead to increases in total incurred losses by decreasing caution and increasing the frequency of risky activity. ${ }^{39}$ This

\author{
Needle exchange \\ Conjugal visits for prisoners \\ (substitutes generally safer \\ heterosexual acts for less \\ safe anal intercourse)
}

Isolation of seropositives (variety of forms) Licensing of prostitutes

(This table includes only interventions which could be expected to have some impact on HIV transmission. Many other interventions have been suggested, including mass testing of teachers and the refusal of parole to HIV-positive inmates, which do not seem to present any significant benefits.)

30. Legalizing heroin, for example, might reduce specific risk while increasing frequency.

31. If potential heroin users are deterred by the threat of AIDS, making clean needles available may increase frequency just because it reduces specific risk. The net effect on transmission of changing two factors in opposite directions remains unclear until the magnitude of the changes is specified.

32. Legalizing heroin might protect currently infected IV users from further exposure to HIV and other pathogens, thus decreasing their rate of disease expression.

33. Even if legalizing heroin would decrease the overall number of transmissions via IV drug use, what would be the effects on the health and welfare of the new crop of heroin users, and on their performance as family members, neighbors, and citizens? Would existing heroin users benefit from legalization in ways other than avoiding HIV infection, and would some of those benefits flow through to others?

34. The legalization of heroin pits the moralists and the libertarians squarely against each other.

35. The author thanks Philip Cook for highlighting the importance of this topic.

36. See Orr, Incentives and Efficiency in Automobile Safety Regulation, Q. REv. Econ. \& Bus., Autumn 1982, at 43, 44-48; Cook, Criminal Incapacitation Effects Considered in an Adaptive Choice Framework, in THE Reasoning Criminal 202, 207-08, 213 (D. Cornish \& R. Clarke eds. 1986).

37. See generally Zeckhauser, supra note 24.

38. See generally Peltzman, The Effects of Automobile Safety Regulation, 83 J. Pol. Econ. 677 (1975).

39. If aircraft safety programs increase the demand for air travel, the number of people killed in air crashes could increase even as the risks per flight or per mile fell. 
need not imply any irrationality on the part of persons taking risks, only that they care about the rewards of the risky activity and the costs of caution as well as the risks they face. Just as the total dollar value of sales may rise as the price of a commodity falls, participation in risky activities may rise so much as risks decrease that total injuries rise as well.

If individuals adjust their behavior to changes in risk, they will, if they are correctly informed and fully self-controlled, make themselves better off by doing so. If the individuals who compensate for changes in risk bore the full burden of their behavior, these adjustments would necessarily improve overall welfare by making the risk takers better off without making anyone else worse off. However, in the case of AIDS, each seropositive person puts future sexual and needle-sharing partners at risk. Thus, risk compensation in the AIDS protection situation will not necessarily be benign. Behavior that is personally rational may be socially devastating.

Moreover, some activities that risk HIV transmission also impose other costs: infection with other diseases, unwanted pregnancy, drug dependency, and crime. Personal precautions against HIV transmission may protect against these side effects as well. The phenomenon of risk compensation means that risk reducing interventions, such as facilitating partner screening, will tend to increase the overall frequency of risky behavior, to cause that frequency to decrease less than it otherwise would, or to diminish the use of other risk reduction methods. Even if risk compensation does not lead to an actual increase in the number of new HIV transmissions, it may still lead to other unwanted results.

\section{G. Measuring Costs and Benefits}

The most important measure of success in fighting the AIDS epidemic is the number of transmissions prevented. Because any intervention to reduce HIV transmissions will cost someone something, it is necessary to have some method to ensure that the costs of safety do not exceed its benefits. Further, there are many different methods to limit the spread of AIDS. Each method has different kinds of costs; policy makers must be able to compare and choose among them. The first step toward addressing these concerns is to quantify the value of preventing a single transmission of HIV.

Some of the costs of the epidemic-health care, lost wages and productivity, the dollar costs of more condoms, and cleaner needles-are easily quantifiable, at least in theory. The costs associated with suffering, death, fear, and loss of liberty are more difficult to quantify. Furthermore, it is often necessary to compare dollar costs to the loss of life. This problem is not unique to AIDS policy; a solid body of work exists to guide policy makers.

When evaluating the worth of preventing an HIV transmission, the largest factor involved is the value of the life saved. The life in question here is a 
"statistical" life and not the life of an identified individual.40 When a town council decides whether to raise property taxes in order to double the budget for life guards at the local pool, its members decide whether the reduction in overall risk is worth the extra money and bad feelings associated with a tax hike, not whether saving the life of a particular neighborhood child is worth the tax increase.

Courts sometimes determine the value of a life by calculating the net present value of the average person's lifetime earnings. ${ }^{41}$ This method is simple to use but provides biased valuations because it considers only the value of labor services sold in the market. ${ }^{42}$ Furthermore, this method is not useful as an approximation of other measures which may be more conceptually valid, but more difficult to evaluate. ${ }^{43}$

Welfare economists attempt to determine the value of a life by measuring the amount people are willing to pay to reduce small risks of death or serious injury to themselves. This is the criterion of "willingness to pay." Economists have developed two methods to estimate an individual's willingness to pay: survey research and "revealed preferences." 44 The survey approach, although it is commonly used to measure willingness to pay for public goods, suffers from the difficulty of reproducing real choices in paperand-pencil exercises. ${ }^{45}$ The revealed preferences method assumes that market behavior reveals the trade-offs individuals are willing to make between safety and money. Usually, wages in occupations involving unequal dangers are compared to determine the premium workers demand for facing increased risk. ${ }^{46}$ These premiums are adjusted for morbidity and mortality rates to determine the amount of premium paid per extra death; this is the willingness to pay for a statistical life. Willingness to pay has been criticized on theoretical grounds, and revealed preference on methodological ones, ${ }^{47}$ but a good alternative does not seem to be available.

Dollar estimates of the value of a life vary widely. ${ }^{48}$ Dillingham ${ }^{49}$ cites studies of labor market behavior which yield values ranging from $\$ 330,000$ to $\$ 5,390,000$ and attributes much of this variation to differences in the defining risk variables. Viscusi notes that different values may represent different

40. Schelling, The Life You Save May Be Your Own, in Problems in Public Expenditure Analysis 127, 127 (S. Chase ed. 1968).

41. Acton, Measuring the Monetary Value of Lifesaving Programs, Law \& Contemp. Probs., Autumn 1976, at 46, 51. Zeckhauser, however, argues that there are shortcomings to courts' use of compensation measures to value lives; these problems include the absence of analytic thinking from the courts' determinations and the lack of "consistency across time or across jurisdictions in the determination of financial amounts for damages." Zeckhauser, supra note 24 , at 450.

42. Acton, supra note 41 , at 53 .

43. For example, the net present value of a person's lifetime earnings does not consider the continuation of that person's enjoyment of family and friends, nor does the measure consider their enjoyment of that person. Id.

44. Id. at 62 .

45. W. Viscusi, Risk by Choice 98 (1983).

46. Acton, supra note 41 , at 62 .

47. Id. at 63. See generally Broome, Trying to Value a Life, 9 J. PuB. Econ. 91 (1978).

48. See generally Blomquist, Estimating the Value of Life and Safety: Recent Developments, in ThE VALUE of LifE AND SAFETY 27 (M. Jones-Lee ed. 1982). 
populations' preferences, and he chooses an estimate of $\$ 2$ million as a "reasonable" willingness to pay to avoid death by workers facing lowmoderate $\left(1 / 10,000 / y r\right.$.) risks of death. ${ }^{50}$ This figure is considerably greater than the present value of future earnings, implying that workers could not afford to buy their own statistical lives at labor market rates. But this only means that most people are risk averse with respect to risks as large as sudden death, which is unsurprising. The high value placed on reducing small risks does, however, mean that a large increase in total social risks, such as an epidemic, will necessarily reduce willingness to pay for risk reduction. Preventing two million premature deaths per year at a cost of $\$ 2$ million each would virtually exhaust the U.S. gross national product. ${ }^{51}$ Thus, if HIV spreads sufficiently, it could reduce the value that the United States as a nation can afford to place on a human life.

The willingness to pay figures derived from labor markets are an imperfect measure of the value of preventing HIV infection because they have to do with sudden accidental death and not uncertain and deferred illness. But HIV infection does not necessarily imply certain death; the virus has not been noted in the human population long enough to determine long term survival rates. Even for those who will develop AIDS, its cost should be discounted, because death is usually years in the future. These two factors will tend to make the willingness to pay to avoid HIV infection lower than the willingness to pay to avoid job site risk.

On the other hand, several characteristics of HIV infection suggest that willingness to pay to avoid instant death underestimates the willingness to pay to avoid HIV infection. Death from AIDS often comes after a long and horrible combination of illnesses; people would probably pay more to avoid this than they would to avoid instant death. Furthermore, everyone who is aware that he is infected with HIV lives in fear of illness and is aware that any risky contact will endanger others. The resulting anxiety can be very unpleasant. Finally, each new HIV infection carries with it the added costs of any retransmission. Although it is unclear whether labor market estimates overestimate or underestimate the value of preventing an HIV infection, it would be difficult to conclude that this value is less than $\$ 1$ million per primary prevented infection.

These estimates have important implications for evaluating anti-AIDS interventions. The costs of any proposed intervention can be compared to the value of any transmissions the intervention can be expected to prevent. Although economic analysis does not make it easier to compare trade-offs involving civil liberties and life, it provides a method for evaluating arguments

49. Dillingham, The Influence of Risk Variable Definition on Value-of-Life Estimates, 23 ECON. INQUIRY 277, 279-80, 291 (1985) (The issue of Economic Inquiry in which Dillingham's article appears is incorrectly printed as part of Volume 24.).

50. W. Viscusi, supra note 45 , at 106.

51. 1987 U.S. GNP $=\$ 4,526,700,000,000$. The U.S. National Income and Product Accounts: Revised Estimates, Surv. of Current Bus., July 1988, at 8, 34. 
over whether "enough" is being spent and for comparing the value of different interventions.

\section{H. The Statistical Logic of Testing}

Screening programs are highly controversial, largely because they threaten the interests of those tested. ${ }^{52}$ Policy makers must also bear in mind other problems when considering implementing, or even allowing, testing of any kind. These problems stem from interaction between the imperfections in the test themselves and the statistical characteristics of tested populations. Groups with different rates of infection will be differently vulnerable to false positive and false negative results. A "false positive" is a test result which indicates that an individual has the condition being tested for, when in fact the person is healthy. A "false negative" is a result which indicates that a person who in fact has the condition does not have it.

In the case of HIV tests, the consequences of both false positives and false negatives are very grave. A false positive, even if it is kept completely confidential, could have devastating psychological and social effects on a healthy person. If such a person began to choose others who tested positive as sexual partners, the results would be particularly grim. A false positive test could become a self-fulfilling prophecy. The consequences of a false negative result are borne largely by those other than the person tested: sexual partners, recipients of blood, or partners in needle sharing, all of whom would be at risk of infection from an infected person believed to be free of HIV.

In addition to the damage caused by particular false positive results, their existence compromises the value of true positive results. A man told that he is infected with HIV, and that he therefore poses a risk to any future sexual partners, has, and may feel, a clear obligation to restrict his behavior. But what is he to make of a finding that he is 72 percent likely to be infected? From a strictly logical viewpoint, given that infection is a probabilistic process anyway, the difference is not great. Psychologically, however, it may be enormous. ${ }^{53}$

A test's resistance to false positives is called its "specificity." 54 Resistance to false negatives is called "sensitivity." 55 A sensitivity of 95 percent means that of 100 persons with the condition in question, 95 will be expected to test positive. A specificity of 90 percent means that of 100 persons free of the condition, 90 will be identified correctly. It is not true that 90 percent of those who test positive on a 90 percent specific test are actually infected or

52. See Bayer, Levine \& Wolf, HIV Antibody Screening: An Ethical Framework for Evaluating Proposed Programs, 256 J.A.M.A. 1768, 1768 (1986) [hereinafter Bayer].

53. The author owes this point to comments at the March 21, 1988, session of the Analytic Methods Seminar of the John F. Kennedy School of Government, made by Arthur I. Applebaum, Fellow in Ethics of the Kennedy School.

54. Barry, Cleary \& Fineberg, Screening for HIV Infection: Risks, Benefits, and the Burden of Proof, 14

L. Med. \& Health Care 259, 261 (1986) [hereinafter Barry].

55. Id. 
that 95 percent of those who test negative on a 95 percent sensitive test are virus free. As an illustration, assume that the condition is present in 0.2 percent of the population being tested. Also, assume that the test for this condition has: (1) a sensitivity of .95 , or a false negative rate of 5 percent; and (2) a specificity of .995 or, a false positive rate of 0.5 percent. Thus, a person with the condition has a probability of .95 of having it detected, and one without it has a probability of .995 of receiving the correct diagnosis. However, only 28 percent of those who test positive will actually have the condition; 72 percent of positive test results will be false. ${ }^{56}$

The reason for this unexpected result is the rarity of the condition in the tested population. Only 50 out of every 10,000 tests on healthy individuals will yield a false result, and 9,500 of every 10,000 infected individuals will test as infected. However, there are so many more healthy individuals than infected ones that the false positives outnumber the true positives. ${ }^{57}$ As the frequency of the condition in the population being tested rises, false negatives will rise in relation to true negatives. For the hypothetical test above, if $\mathbf{5 0}$ percent of those tested were infected, then 5 percent of all negative results, but fewer than 1 percent of all positive results, would be false. Table II (see p. $331)$ illustrates the results of a test with the above characteristics when performed on a population of 10,000 individuals. The first section of the table depicts test results when 20 of the 10,000 are infected. The second depicts the results of the same test when applied to a group in which 5,000 of the 10,000 individuals are infected.

This statistical result has important implications for HIV screening programs. So-called "AIDS tests" currently in use detect the presence of antibodies to the virus-not the virus itself. ${ }^{58}$ Antibody testing is done in two stages: (1) with an inexpensive and relatively simple test known as Enzyme Linked Immunosorbent Assay (ELISA); and (2) for all samples which repeatedly test positive on ELISA, with the Western Blot test. ${ }^{59}$ ELISA alone will yield substantial numbers of false positives in a population with low incidence of infection. Barry estimates that only 11.3 percent of positive ELISA test results will be true positives in a population with a seroprevalence of 0.03 percent $^{60}$ The Western Blot test eliminates most, but not all, of the false positives of ELISA. ${ }^{61}$ Thus, for groups with a very low incidence of disease, such as those about to be married, the current testing procedure would yield a large proportion of false positives even among those "confirmed positive" by the second test. ${ }^{62}$

56. See Table II, infra 331

57. The false positives are fewer than $1 \%$ of the healthy members of the tested population. The true positives comprise $95 \%$ of the sick members of the tested population.

58. Barry, supra note 54 , at 260.

59. Id.

60. Id. at 263.

61. Id. at 262 .

62. Barry, Cleary and Fineberg estimate $30 \%$. Id. at 263. 


\section{TABLE II}

\section{False Positives and False Negatives}

Part 1: Test Results When 20 in 10,000 are Infected

Test Sensitivity $=95 \%$, Test Specificity $=99.5 \%$

\begin{tabular}{|c|c|c|c|c|}
\hline & Total & Negative Result & Positive Result & $\begin{array}{l}\text { False Results as \% of } \\
\text { All Results in Group }\end{array}$ \\
\hline Infected Individuals & 20 & 1 & 19 & 5 \\
\hline Uninfected Individuals & 9980 & 9930 & 50 & 0.5 \\
\hline Total & 10,000 & 9931 & 69 & 0.5 \\
\hline $\begin{array}{l}\text { False Results as \% } \\
\text { Of all Results }\end{array}$ & - & 0.01 & 72.5 & 0.51 \\
\hline
\end{tabular}

Part 2: Test Results When 5,000 in 10,000 are Infected

Test Sensitivity $=95 \%$, Test Specificity $=99.5 \%$

\begin{tabular}{l|c|c|c|c|}
\multirow{2}{*}{\begin{tabular}{l} 
Infected Individuals \\
\cline { 2 - 5 }
\end{tabular}} & 5000 & 250 & 4750 & 5 \\
\hline Uninfected Individuals & 5000 & 4975 & 25 & 0.5 \\
\hline Total & 10,000 & 5225 & 4775 & 2.75 \\
\hline $\begin{array}{l}\text { False Results as \% } \\
\text { of All Results }\end{array}$ & - & 4.8 & 0.5 & 2.75 \\
\hline
\end{tabular}

As the prevalence of the condition rises, so does the probability that a positive test result will be correct. At the same time, the probability that a negative test result is correct falls as the condition prevalence rises. Thus, knowledge about risk factors is relevant even after test results are available: in the case of AIDS, a heroin user with a positive test result is much more likely actually to be infected than a monogamous heterosexual.

Populations having high seroprevalence present a greater risk of false negative test results. ${ }^{63}$ This reduces the assurance provided by any negative test result. In addition to false negative test results due to testing errors and test design, there are unavoidable false negatives due to the $\operatorname{lag}^{64}$ between infection with HIV and development of antibodies. During this lag, individuals who are infected will not register as such on any antibody test. ${ }^{65}$ Many members of high risk groups, such as male homosexuals and IV drug users, also have other antibodies in their blood which tend to confound the current tests. ${ }^{66}$ The false positive rates for high risk groups are higher than for the general population, although the proportion of all positive results which are accurate remains higher for those groups than for lower risk groups. Table III demonstrates the results for both high risk and low risk groups of a

63. Id. at $263-64,266$.

64. This lag averages three to twelve weeks. Id. at 262.

65. Id.

66. Id. at $261,262$. 


\section{TABLE III}

\section{False Results When Specificity and Prevalence Vary}

Part 1: Test Results When 20 in 10,000 are Infected Test Sensitivity $=95 \%$, Test Specificity $=99.5 \%$

\begin{tabular}{l|c|c|c|c|}
\multirow{2}{*}{ Infected Individuals } & \multicolumn{1}{c}{ Total } & Negative Result & Positive Result & $\begin{array}{c}\text { False Results as \% of } \\
\text { All Results in Group }\end{array}$ \\
\cline { 2 - 5 } & 20 & 1 & 19 & 5 \\
\hline Uninfected Individuals & 9980 & 9930 & 50 & 0.5 \\
\hline Total & 10,000 & 9931 & 69 & 0.5 \\
\hline $\begin{array}{l}\text { False Results as } \% \\
\text { Of all Results }\end{array}$ & - & 0.01 & 72.5 & 0.51 \\
\hline
\end{tabular}

Part 2: Test Results When 5,000 in 10,000 are Infected Test Sensitivity $=95 \%$, Test Specificity $=95 \%$

\begin{tabular}{l|c|c|c|c|}
\multirow{2}{*}{\begin{tabular}{l} 
Infected Individuals \\
\cline { 2 - 5 }
\end{tabular}} & 5000 & 250 & 4750 & 5 \\
\hline Uninfected Individuals & 5000 & 4750 & 250 & 5 \\
\hline Total & 10,000 & 5000 & 5000 & 5 \\
\hline $\begin{array}{l}\text { False Results as \% } \\
\text { of All Results }\end{array}$ & - & 5 & 5 & 5 \\
\hline
\end{tabular}

For some conditions, including HIV infection, test specificity can decline as condition prevalence rises. This means that the percentage of uninfected individuals testing positive will be higher in "high risk groups." However, as the table demonstrates, at reasonable changes in specificity high condition prevalence more than outweighs this factor, and a positive test is still far more likely to be correct among high risk populations than it is among low risk groups.

hypothetical medical test which is more likely to yield a false positive result for the high risk group.

All current tests yield some false results of both types; there is no infallible test. The condition tested for-the presence of virus genotype in T4 cells-is not directly observable. Furthermore, attempts to culture the virus from an individual's blood are also subject to false negative results. ${ }^{67}$ Because positive results are more likely to be false in low risk groups and negative results more likely to be false in high risk groups, accurate information about a testee's sexual, drug, and transfusion history would improve test accuracy. Some gayrights advocates fear that this is another attempt to single out homosexuals for discrimination. Furthermore, test administrators have to decide where to set critical values on the Western Blot confirmatory test, which yields not a simple "yes" or "no" but a range of values. ${ }^{68}$ The higher the reading required as a confirmation, the more selective, but the less sensitive, the test will be. Test administrators also must decide what to tell testees whose results

67. Id. at 260 .

68. Id. at 262 . 
fall in an ambiguous range near the critical point. Developing extremely accurate tests for low risk populations would be a very valuable activity, and more accurate tests should be available soon. ${ }^{69}$ The development of these tests should eliminate many of the problems associated with false positives and false negatives. It will not, however, mitigate the concerns about civil liberties and confidentiality.

Although screening offers epidemiological information, it does little directly to contain the virus's spread. Screening could be used merely to subject testees to harassment and discrimination, neither of which helps control the epidemic. But there are situations in which screening can assist in the prevention of some HIV transmissions. Prison inmates, for example, could be segregated by serum status. Infected prostitutes could be deterred or incapacitated from further practicing their trade. In these cases, the relative frequency of false positives is low, due to the prevalence of HIV among the groups being tested, and the benefits of reducing contacts between infected members of these groups and others are substantial. The questions to be asked about any screening proposal are whether its epidemic control benefits justify its costs, in terms of money, personal liberty, and social strife, and whether it is the least cost way to achieve those benefits. ${ }^{70}$

\section{Identification Methods}

All sexually active individuals have an interest in knowing the serum status of their prospective sexual partners. But even if everyone knew his or her own status, one could not assume completely accurate self-revelation. There would be more assurance about prospective partners' status if testing were supplemented by documentation.

Population groups and geographic areas vary in the benefits and costs that would result from serum status identification programs. The seroprevalence and transmission rates in some groups might justify the costs entailed while in others it might not. Because of the externalities associated with infection and illness, the social benefits from reduced HIV transmission will exceed the private benefits in all population groups. Thus, rational individual choice and market provided services may not deliver an optimal level of transmission reduction; the market's failure to support an identification scheme does not indicate that the costs of such a scheme exceed its benefits.

At current rates of HIV infection among non-IV-drug-using heterosexuals, it is hard to imagine how any such system could be established or sustained among the population at large, and such a proposal would run into massive resistance among homosexuals. ${ }^{71}$ Speculation on how such a system might operate has, therefore, a somewhat science-fictional character. But thinking about serum status identification may be a useful heuristic for thinking about

69. Cheap HIV Tests Imminent, New York Researcher Says, AIDS Pol'y \& L., Apr. 8, 1987, at 6.

70. See Bayer, supra note 52, at 1769.

71. See R. Shilts, And the Band Played On: Politics, People, and the AidS Epidemic 539-43 (1987). 
the dynamics of sexual sorting in the presence of HIV as a risk. Moreover, the continued growth of infection rates might, in the future, begin to give practical significance to the exercise.

An alternative to an open-ended identification system is the closed-ended system of "safe sex" and "AIDS-free" clubs, or the HIV-screened dating service. Such organizations have begun to appear, only to be denounced by AIDS advocacy and education groups. Authorities have broken up at least one club after allegations by such groups that the clubs cannot truly guarantee safety and that they may in fact contribute to so much risk compensating behavior as to increase transmission rates. ${ }^{72}$ The latter claim seems overdrawn, but the closed nature of such clubs limits the number they are likely to protect, and the risk of exposing participants through outside contact is still greater than it would be under a more universal system.

Any identification scheme has three basic problems: accuracy and veracity, risk compensation, and the potential for discrimination against those who test positive or merely participate in a screening program. Imagine the simplest system. Testing centers could be established which would issue to any individual who tests negative for HIV antibodies a dated document attesting to that fact. Individuals would be urged to compare documents before engaging in risky contacts. To help ensure accuracy, the government or another institution would either sponsor or supervise the testing program..$^{73}$ The documents would have to be protected against both counterfeiting and borrowing. Documents with holographs would greatly increase the difficulty of making counterfeits; photographs could limit the extent of card sharing.

Counseling certain participants about potential false positive and false negative test results would present great difficulties. Because participants could not be expected to volunteer sensitive background information, interpreting ambiguous test results would be difficult. Officials would have to weigh the relative merits of placing subjects with ambiguous results in the infected or the uninfected category. All ambiguous testees could be classified as infected and provided intense counseling on the test results and repeated testing to attempt to determine true serum status. Conversely, they could be placed in the uninfected category and counseled on the potential danger they may pose to others.

The more conservative approach, placing all ambiguous results in the infected category, would have a number of costs if serum status identification became commonplace among the sexually active. Uninfected individuals with ambiguous test results would find themselves severely restricted in their choice of sexual partners and it would be difficult for them to marry or have

72. Black, Shannon Halts Proposal for AIDS-Free Social Club, Boston Globe, Aug. 8, 1987, at 17, col. 4.

73. However, the sponsorship of such a program by any health insurer-for example, the Red Cross-would require strong legal barriers to the use of the data for insurance purposes and to communication of the data to employers. Many individuals, especially members of high risk groups, might still distrust such a system because of its sponsorship; in this case, the solution might be to have advocacy groups among, for example, the homosexual community run the system. 
children. Further, if they did engage in sex with seropositive individuals, they would be at a substantial risk of actually becoming infected. If all ambiguous test results were assigned to the uninfected category, the opposite problems would arise. Seropositive individuals could spread the infection to partners who believed them to be healthy. Also, women who believe that they are healthy could become pregnant and transmit the disease to newborns. Such incidents would undermine the effectiveness of the entire system.

Regardless of the classification chosen, there would be two kinds of unavoidable false negative results: persons infected too recently to have developed antibodies and persons infected between the test date and the time of contact. ${ }^{74}$ Sex with a tested "negative" would not be perfectly safe, only safer than sex with an untested individual.

False positive and negative test results could also lead to "test shopping": persons who initially tested positive seeking repeated tests in hopes that a negative result would arise due to test errors. Such retesting could be prevented only by maintaining a register of all test subjects and prohibiting retesting of those already designated positive. Although such a register would be analogous to the procedure the Red Cross follows with respect to blood donors, fear of breaches of confidentiality would discourage many from taking the test. This problem would tend to diminish in importance as the sensitivity of the tests improved.

A serious problem with any card system would be restricting such cards to their intended purpose-sexual sorting by serum status. Display of a serumnegative card could become a formal or informal requirement for employment and housing. Legal controls on requirements to display such a card would be relatively ineffective as long as it remained possible for a serum-negative individual to voluntarily display it any time. Failure to voluntarily display it would attract an unfavorable inference.

Unless cards were universally carried, it would be quite difficult to distinguish a seropositive individual from a mere nonparticipant in the system. Since no one has any incentive to falsely claim infected status, there would be no purpose in issuing cards showing positive serum status; therefore, the cards would effectively confer a privilege. An ingenious solution to part of this problem is to encourage everyone to carry a pendant or bracelet testifying to participation in the testing scheme. ${ }^{75}$ Those with negative test results would be issued pendants capable of being opened to display the negative testing documentation with its date. In this way, a stigma could be placed on nonparticipation-thus inviting as many as possible to join the scheme-without immediately stigmatizing those with unfavorable test results. Possession and display of the pendant or bracelet would be an open invitation to compare notes before engaging in otherwise risky contact. This

74. This latter risk would be minimized if participants limited their contact to other participants; the rate of new infections among diligent card users would not be zero, but it would be very small.

75. The Checkmate Commitee, The Checkmate Proposal: A Summary of the Book in Progress 19-20 (1987). 
scheme, however, does not create a technological barrier against the risk of being coerced into displaying one's negative status.

A little additional technical ingenuity could greatly alleviate this problem. Because the purpose of the system is not to allow seronegatives to demonstrate their freedom from infection, but to prevent risky contact across seropositive/seronegative lines, it is never necessary for anyone to be able to demonstrate his or her own serum status, but only to have an unambiguous way to identify the relative serum status of a potential pair. The ideal device in this case would be a "smart card"- a microchip, an interface device, and a display-which would not disclose its owner's serum status. When any two smart cards were linked, however, they would display green lights if each had the same reading and red lights if they had different readings, or if either card was outdated. Such devices could be mass produced for about $\$ 25$ each. ${ }^{76}$ In addition to emphasizing the symmetry between seropositive and seronegative persons, such a system would give technological backing to legal prohibitions on demands for unilateral displays of seronegativity. To abuse the system, a would-be discriminator would have to actively participate in a crime. Thus, law and custom could restrict the comparison of devices to intimate situations. A third party watching the comparison would learn next to nothing about the status of each participant because a red light would mean only that one or the other participant was seropositive or had an outdated card.

If at some point in the future conditions called for a system of technologically assisted partner screening as an epidemic control device, there would remain the problem of how to introduce the custom of acquiring, displaying, and using such devices. Should the display of the device itself be open? How could one prevent mere possession of such a device being taken as an admission of an intent to engage in promiscuous sex or membership in a high risk group? If the government will not sponsor the program, who will? Would any sponsor be able to gain the necessary trust of the populace?

"Smart cards" carrying medical history information have been proposed before to simplify the history and physical process in routine medical care, to ease records transfer among health care providers, and to avoid life threatening mistakes in emergencies. Combining this function with HIVstatus identification could reduce the net cost of the HIV screening application and greatly improve the cards' acceptability among low risk populations. But the only plausible sponsor for such a system would be the health insurance industry. Such sponsorship would be greatly problematic as long as health insurers retain their own financial interests in learning, and in some cases communicating to employers, individuals' HIV infection status.

Despite problems with test sensitivity, specificity, and lags between infection and antibody production, a card system would reduce enormously the riskiness of any given level of promiscuous sexual contact. However, risk compensation could be a problem. If reliance on a card system were

76. Confidential conversation. 
substituted for other risk control measures, the system's effect on the transmission rate would be ambiguous. If a card system led to increased numbers of contacts or decreased condom use, it would tend to increase unwanted pregnancy and the transmission of other diseases.

\section{J. Three Views of the AIDS Policy Debate}

Controlling the AIDS epidemic does not create the same kind of policy debate as deciding how much to spend on building roads or choosing the patent life to give to new drugs. Virtually everyone engaged in the road building or patent life debates assumes that the best decision is the one that leads to the best results and that the debate consists of arguing about what the consequences of different options will be and how they ought to be valued. Philosophically, and as applied to the entire subject of moral choice, this view is called "consequentialism." 77 As taught professionally in schools of public policy, it goes by the name of "policy analysis." In confronting AIDS, two other views of the nature of public choice and styles of policy debate compete with consequentialist policy analysis.

One view asserts that some actions of private persons are virtuous, while others are (in the root meaning of the word) vicious; that public authority should promote virtues and suppress vices; and that policies to do so are "right" and their opposites are "wrong" in ways not fully reducible to their good or bad consequences, or that toleration of vice inevitably has bad consequences even when the causal chain cannot be traced. The content of the categories of virtue and vice may be held to follow from definitions of "right" and "wrong,"78 from fundamental statements about human nature, 79 or they may be taken to represent divine commandments revealed by one or another sacred text or religious tradition. ${ }^{80} \mathrm{~A}$ philosophically distinct, but operationally similar, view holds that the particular views about virtue and vice held by any society are arbitrary, but that the maintenance of such traditional views is a central task of political institutions because it is essential to social well-being. ${ }^{81}$ The notion that "right" and "wrong" are logically independent of "good" and "bad" defines a "deontological," as opposed to a "consequentialist," view of moral choice. Such views are likely to be called "moral" by their proponents and "moralistic" by others. This article will refer to this deontological view as "moralist" beliefs or "moralism."

77. Confusingly, consequentialism is often referred to as "utilitarianism," which is properly the name of the version of consequentialism holding that the only relevant consequences of an action are its effects on the pleasures and pains of individuals.

78. For an example of such moralist thought, see I. Kant, Fundamental Principles of the Metaphysics of Ethics (O. Manthey-Zorn trans. 1938).

79. This seems to be the view that Plato attributes to Socrates in the Phaedo. It is also the traditional reading of Aristotle's Politics and Nicomachean Ethics.

80. For an example of such an interpretation, see generally T. Aquinas, ON THE TRUTH OF THE Catholic Faith, Book 3 (V. Bourke trans. 1956).

81. See generally M. Oakeshott, Rationalism in Politics, and Other Essays (1962); E. Burke, Reflections on the Revolution in France (C. O'Brien ed. 1968). 
The other nonconsequentialist view comes from those who oppose direct state interference with private choices when this interference is based on moralist grounds. This view may derive from a belief that individual self-rule is a human right and that state interference is morally wrong apart from its consequences, ${ }^{82}$ or it may rest on the proposition that the political process will decide these matters badly and should therefore be forbidden to decide them at all, even if in some instances moralistic laws may have good effects. ${ }^{83}$ Some American proponents claim that this view represents the Founders' intention and is enshrined in the Constitution and its amendments, particularly the Bill of Rights and the fourteenth amendment. ${ }^{84}$ In the text that follows, all of these views will be referred to as "libertarian."

Moralism, libertarianism, and consequentialism are each subject to telling criticism. Moralism is always a particular moralism, and its introduction into policy debate will always be seen by those who do not share it as representing an attempt to capture state power for sectarian ends. By its nature, moralism tends to be blind to the bad consequences that imperfect compliance with the laws may cause. Too many moralists are tinged with ill will toward those of bad character, as they define it. ${ }^{85}$

Libertarianism fails to recognize the problems of self-command ${ }^{86}$ and involves an excessively narrow view of the consequences of unconstrained private pleasure seeking on the competence and public spirit of those on whose performance as parents, neighbors, and citizens any republic must rely. ${ }^{87}$ The libertarian fear of undue state interference lends libertarians to subject proposals designed to control "vice" to a nearly impossible standard of demonstrated harm. ${ }^{88}$

Consequentialist policy analysis is inevitably biased toward the measurable, short term effects of the policies it considers. The well-trained policy analyst will omit from his or her calculations the slow effects of policies on norms and customs. However, if private character is important and influenced by the public action under consideration, this will lead to mistakes. The policy-analytic tradition tends to neglect the effect that merely announcing a policy can have on social and private character. The process of policy making itself, through the rhetoric employed and the respect paid or

82. See generally R. Nozick, ANarchy, State AND Utopia (1974).

83. This is so because moralist arguments are hard to resolve and the passions they generate tend to distort political discourse. An example of a work which adopts this view is J. MiLl, ON LiBERTY (1859) (G. Himmelfarb ed., rev. ed. 1984).

84. Dorsen, Introduction, in Our Endangered Rights viii-xiv (N. Dorsen ed. 1984).

85. For an eloquent statement of the dangers posed by moralistic ill will to republican institutions, see Lincoln, Temperance Address of February 22, 1846, in Collected Works of Abraham LiNCOLN 271 (R. Basler ed. 1953).

86. See generally Schelling, The Intimate Contest for Self-Command, The Pubuc Interest, Summer 1980, at 94; see also Schelling, Ethics, Law, and the Exercise of Self-Command, in 4 The Tanner Lectures on Human Values 43 (S. McMurrin ed. 1983) (discussing failure to recognize the problems of selfcommand).

87. See generally Kleiman, Liberalism and Vice Control, 6 J. Pol'y Analysis \& Mgmt. 242 (1987).

88. See, e.g., Richards, Liberalism, Public Morality, and Constitutional Law: Prolegomenon to a Theory of the Constitutional Right to Privacy, Law \& Contemp. Probs., Winter 1988, at 123. 
denied persons and groups, may directly influence preferences and customs. ${ }^{89}$ Further, policy analysis treats the process of public decisionmaking as a rational actor to which prescriptive advice can be given rather than as one social process among many, ruled by its own descriptive laws. Thus, traditional policy analysis ignores the importance of public or constitutional taboos on the process of public choice. ${ }^{90}$

Although moralist and libertarian strains run deep in American thought, political arguments in the United States are usually framed in consequentialist terms. By attempting to provide consequentialist rationales for positions chosen on other grounds, both moralists and libertarians may be forced into unjustified factual assertions and analytical errors. Both groups represent values that are important for informed public decisionmaking, but values should not be allowed to masquerade as facts and inferences.

\section{III}

\section{Applications}

The balance of this essay will examine the categories of HIV transmission, the range of possible interventions, and the consequences of those policies for the sick, the infected, and the uninfected. It will evaluate the likely responses to proposed interventions of those who enter the debate as guardians of public morals and civil liberties. The program to control HIV in the blood supply is an example of quick and effective action to limit transmission. This program was successful because of technically favorable circumstances and a (relative) lack of political controversy. Unfortunately, these circumstances are not reproduced for the problems of sexual and drug-related transmission.

\section{A. Blood Transfusion}

HIV can be transmitted by the transfusion of blood from an infected to an uninfected person. Steps have therefore been taken to screen donors and to test blood. Currently, those measures are largely noncontroversial, because virtually no one considers giving blood to be a personal right, nor receiving blood to be a vice. Matters might have been very different if many people had shared the view of the Jehovah's Witnesses that blood transfusion falls under the Biblical proscription against "eating blood." 91 Proponents of that view would have pointed out that AIDS was divine punishment for the sin of transfusion and that it could be controlled only by reducing the number of transfusions. The screening of donors would have been regarded as a technological solution to a behavioral problem, a solution likely, due to a risk-

89. For a critique emphasizing the independent importance of proclaimed policies and political processes, see S. Kelman, What Price Incentives? 153-55 (1981).

90. For a classical statement of the policy-analytic tradition, see E. Stokey \& R. Zeckhauser, A Primer for Policy Analysis (1978).

91. Leviticus 17:10-14; see also H. Botting \& G. Botting, The Orwellian World of Jehovah's WiTNESSES 29-30 (1984). 
compensation-induced increase in transfusion activity, to accelerate the spread of other transfusion-borne diseases such as hepatitis.

In practice, however, no one proposed reducing the frequency of transfusions. It was possible to reduce specific risk of transfusions of various blood factors, but not of whole blood. ${ }^{92}$ The only remaining option was the segregation of the blood of HIV positive donors from recipients.

The Red Cross uses a two-step process to keep the blood supply free of HIV. ${ }^{93}$ First, all prospective donors are given literature which reflects the most current understanding of HIV transmission and infection risks. ${ }^{94}$ Red Cross personnel make sure that potential donors read the material in their presence, and encourage anyone who believes himself or herself to be at risk to leave before completing the rest of the process. ${ }^{95}$ Those who do not leave are then asked to fill out a screening questionnaire, and any who appear to be at risk for HIV are again encouraged to leave. ${ }^{96}$ At this juncture, all potential donors are given the opportunity to indicate on a "confidential unit exclusion" form that they wish to donate but do not want their blood transfused; ${ }^{\mathbf{9 7}}$ this allows people in situations where donating blood is a social effort (such as employee blood drives) to avoid stigmatization while still protecting the blood supply.

The second stage of the Red Cross screening process involves the donated blood itself. Donated blood is first tested with ELISA, and blood which tests positive for HIV antibodies is tested a second and third time. ${ }^{98}$ If a positive finding is confirmed by ELISA two out of three times, the blood in question is thrown out, and the donor's name is flagged in the confidential Donor Deferral Registry so that any subsequent donations can be discarded. ${ }^{99}$ The Western Blot test is then conducted to verify the results of the ELISAs. ${ }^{100}$ If the final test is positive, the donor is notified that he or she is seropositive and should not donate. ${ }^{101}$ If the positive finding is not confirmed, the donor is not notified, due to the possibility of false positive results, but his or her name remains in the Donor Deferral Registry. ${ }^{102}$ Thus, the notion that the Red Cross "tests blood, not people" is at best a half-truth, but no one has chosen to make an issue of it.

92. N.A.S., supra note 1 , at 54 (HIV does not survive a heating process which leaves the factors intact.).

93. American National Red Cross, Blood Services Directive ("B.S.D.") 5.29: Donor Processing and Management 2-3, attachment V-2 (rev. Apr. 1988); B.S.D. 4.56: Notification, Counselling and Medical Evaluation of Donors with Repeatably Positive HTlV iII Antibody Test Results 1-2 (May 1985); B.S.D. 6.52: Testing for HTLV-III Antibody and Disposition of AIDS-Suspect Blood 3-4 (rev. Feb. 1985).

94. Conversation with Peter Page, M.D., Director, American Red Cross Blood Services (Sept. 1987).

95. Id

96. Id.

97. Id.

98. Id

99. Id.

100. Id

101. Id

102. Id. 
The current smooth functioning of the donor deferral and blood testing system stands in sharp contrast to the vigorous debate it aroused when first proposed. The blood banking industry, concerned about costs, bad publicity, the loss of potential donors, and consequent possible blood shortages, put up a strong fight against the notion that AIDS could be spread through the blood system. At the same time, some gay-rights organizations opposed any screening by risk history and any testing of donated blood due to concerns about the confidentiality of donor deferral lists and reinforcement of the connection in the public mind between homosexuality and the spread of the virus. ${ }^{103}$ Partly as a result, it was more than a year after the evidence of transfusion related cases was clear before the announcement of the first donor deferral guidelines. ${ }^{104}$

The prescreening of risk groups and the flagging of donors who have tested positive are necessary because of false negative results, particularly those due to the lag in antibody development. A recently exposed donor may test negative although his blood carries the virus. ${ }^{105}$ The spread of HIV outside the currently identified risk groups will severely limit the effectiveness of prescreening in protecting the blood supply.

Compliance with Red Cross requests for risk group members not to donate appears to have been very good. The combination of donor deferral and HIV testing has greatly reduced the probability of transmission of HIV by transfusion. ${ }^{106}$ The reduction in the probability of receiving infected blood has overwhelmed any compensating increases in transfusion frequency. No one with any significant influence regards the blood question as one of public morality. Although some of the steps taken appear to have the characteristics which worry libertarians and gay-rights groups under other circumstances, no one feels threatened by them in the blood bank context. This contrasts sharply with the more controversial routes of infection.

\section{B. Heterosexual Activity}

Men can transmit HIV to women in anal, vaginal, and oral intercourse. ${ }^{107}$ Women can transmit to men in anal and vaginal intercourse. ${ }^{108}$ In heterosexual activity, the specific risk to a male under U.S. conditions may be substantially lower than the specific risk to a female. ${ }^{109}$ Conditions in Central Africa are different; there, AIDS spreads predominantly through heterosexual

103. R. ShiLts, supra note 71 , at 170-71, 220-26.

104. Id. at 243.

105. This has happened at least once. See Centers for Disease Control, Transfusion-Associated Human T-Lymphotropic Virus, Type III/Lymphadenopathy-Associaled Virus Infection from a Seronegative Donor-Colorado, 35 Morbidity \& Mortality WeEkLY ReP. 389, 389-90 (1986).

106. N.A.S., supra note 1, at 53 ("Self-exclusion of donors who are members of high risk groups . . began in 1983 and no doubt reduced the risk of exposure to HIV among transfusion patients.").

107. Id. at 6 .

108. Id.

109. E. Nichols, Mobilizing Against AIDS 27 (1986). But see Mueller, The Epidemiology of the Human Immunodeficiency Virus Infection, 14 Law Med. \& Health Care 250, 256 (1986). 
contact, with men and women at about equal risk. ${ }^{10}$ The higher incidence of lesion-producing skin diseases and of untreated venereal disease in Central Africa may account for the difference.

With homosexual and IV spread limited to comparatively small subpopulations and the blood supply currently under reasonable control, the rate and pattern of heterosexual spread will determine whether AIDS in the United States will claim "only" hundreds of thousands of lives or many millions. Recent news is mildly encouraging.

If bisexuals and IV-using prostitutes were spreading the virus across a broad population spectrum, and if the heterosexual population, thus seeded, were sustaining an internal epidemic with the very short doubling times characteristic of the early stages of the epidemic among homosexuals, the rapid spread of seroprevalence in the general population would be reflected in AIDS among newborns, even if not reflected in clinical AIDS cases due to the long incubation period. ${ }^{11}$ That is not happening. The vast majority of children born with AIDS are the children of IV-using mothers or of mothers with IV-using sex partners. ${ }^{112}$

This relatively good news may mean only that society has some time to deal with the problem. If the expected lifetime transmission rate through heterosexual contact is greater than one, ${ }^{113}$ seroprevalence in the general population will continue to rise until saturation among relatively careless subpopulations of heterosexuals, and epidemic-driven behavioral change, pushes that rate below one. The number of new infections in each time period will tend to rise, ceteris paribus, as the rise in seroprevalence increases the chance that a randomly selected heterosexual partner is infected. The disease has a great deal of time to spread before subjective appreciation of reality of heterosexual transmission ${ }^{144}$ generates major behavioral changes, particularly if the development of the disease among infected individuals is slow. A glacier does not move as fast as an avalanche, but it gets the job done.

No one knows how far or how fast the disease will spread, partly because no one knows the contact specific risk of different forms of sexual contact.

110. N.A.S., supra note 1, at 75; Clumeck, Robert-Guroff, Van De Perre, Jennings, Sibornana, Demol, Gran \& Gallo, Seroepidemiological Studies of HTLV-III Antibody Prevalence Among Selected Groups of Heterosexual Africans, 254 J.A.M.A. 2599, 2599 (1985).

111. Of children born to seropositive mothers, estimates of the proportion which will be born infected with HIV vary. See N.A.S., supra note 1, at 56-57 (citing Scott, Fischel, Kimas, Fletcher, Dickinson, Levine \& Parks, Mothers of Infants with Acquired Immunodeficiency Syndrome: Evidence for Both Symptomatic and Asymptomatic Carriers, 253 J.A.M.A. 363, 363-66 (1985) (65\%); also citing Centers for Disease Control, Recommendations for Assisting in the Prevention of Perinatal Transmission of Human $T$. Lymphotropic Virus Type III/Lymphadenopathy Associated Virus and the Acquired Immunodeficiency Syndrome, 34 MORBIDITY \& MORTALITY WEEKLy Rep. 721,731 (1986) (estimates vary from 0\% to 22\%)).

112. See Rogers, Thomas, Starcher, Noa, Bush \& Jaffe, Acquired Immunodeficiency Syndrome in Children: Report of the Centers for Disease Control National Surveillance, 1982 to 1985, 79 PEDiatrics 1008, 1010 (1987) (Table 1 at 1010 describes risk factors associated with pediatric AIDS cases).

113. This would occur if, on average, each infected heterosexual is responsible for infecting even a fraction more than one person.

114. This is likely to come only when acquaintances or celebrities who are heterosexually infected start to sicken and die. 
For example, if the specific risk to the female in unprotected vaginal intercourse without any potential co-factors turns out to be near 0.001 (onetenth of one percent), and if the specific risk to the male is even smaller, the disease will not spread very rapidly among non-IV-using heterosexuals. ${ }^{115}$ It is possible that specific risk rises in proportion to the proportion of the infected partner's T4 cells which carry the HIV genome. This in turn rises almost exponentially with the time from initial exposure. ${ }^{16}$ If that were true, specific risk in heterosexual contact would tend to increase with time, and the lack of cases among newborns outside heroin-using areas might prove to be a false indicator of the long term risk of a very wide epidemic in the United States.

The greater the specific risks, the more likely the infection is to spread. However, the fact that heterosexual intercourse is less dangerous to men than it is to women is a mixed blessing, because it reduces the self-interest of males in safer practices and throws much of the burden of responsibility for epidemic control on females. This may tend to produce a move back in the direction of pre-Pill sexual practices, with AIDS substituting for pregnancy as the topic of greater concern to women than to men. Since there is still great uncertainty about specific risks, it is still possible that controlling heterosexual spread will be a major national health need. Within minority populations in some urban areas, the importance of doing so is already clear.

Changes in frequency, specific risks, and the contact rate between infected and uninfected individuals could reduce HIV transmission through noncommercial heterosexual contact. These changes might result from changes in sexual customs and practices, which are subject to public intervention of at least two kinds: (1) actions directly imposing punishments and rewards on sexual activity and its observable consequences; and (2) actions which affect the form and content of what is heard and seen about sex in the schools and in the media. A number of possible changes in both laws and messages could help reduce HIV spread. But the other results of such actions are likely to be sufficiently great and controversial that their merits as epidemic control measures will be almost irrelevant to their political fate.

The proportion of heterosexual contacts involving one infected and one uninfected party does not depend solely on changes in overall sexual mores

115. If the specific risk to the female is $1 / 1000$, then a female choosing a new partner at random from a male heterosexual population with a seroprevalence of $0.5 \%$ every six months for twenty years and having unprotected intercourse with each partner three times each week would face a risk of infection over that period of $1-\left[1-\left[0.005 *\left[1-(1-0.001)^{7 \kappa}\right]\right]\right]^{+1}=0.0149$, or just under $1.5 \%$.

One other encouraging note, though not yet verified, is the possibility that a genetic susceptibility to infection exists and is tied to a similar susceptibility to illness once infected. See supra text accompanying note 2 . This would imply that current measures of specific risk and disease expression rates are biased upward due to sample selection, and that rates of infection and of illness will decline in the future.

116. Telephone conversation with David Kanouse, Senior Scientist, Rand Corporation (Feb. 1988). 
due to changes in laws and messages, ${ }^{117}$ it can also be influenced by policies making it easier or more difficult for potential bedmates to determine each other's HIV status.

1. Reducing Frequency. Other things held constant, reducing the frequency of sexual contact between men and women would probably reduce the rate of heterosexual transmission of HIV. The sexual counterrevolution which started with the fear of herpes seems to have picked up some steam from the fear of AIDS. ${ }^{118}$ Concern about AIDS is likely to continue to grow, ${ }^{119}$ but little is known about what causes sexual frequency to vary over time or across cultures or populations. Serious research about who does what, how often, and with whom sexually is almost nonexistent; the outdated and methodologically laughable Kinsey reports ${ }^{120}$ have not been improved on, or even repeated. In "the good old days, when sex was dirty and the air was clean," was overall sexual frequency lower? No one knows. A large part of the AIDS research budget should be devoted to behavioral studies to identify some of the determinants of sexual behavior and perhaps find ways to influence behavior to reduce the transmission of HIV.

The mix of messages about sex conveyed by the mass media and schools is one plausible candidate for intervention. If changing the frequency of food cues affects food consumption, ${ }^{121}$ why should not changing the frequency of sex cues influence the overall rate of copulation? How plausible is it that the deluge of pro-sex messages has no effect on sexual frequency?

Sex education directed at controlling HIV transmission could focus on reducing the frequency of sexual contact and on raising the age of sexual initiation. Such messages, presented in a fashion similar to current anti-drug messages, would please some moralists. But the effectiveness of anti-drug messages is unknown and there is no way to predict the effects of an anti-sex campaign. Such a campaign might tend to increase specific risk by interfering with the technical side of sex education. Whether one thinks that this side effect would be good or bad partially depends on empirically answerable questions ${ }^{122}$ and partly on evaluative ones. ${ }^{123}$

The mass media give messages relevant to frequency, the mix of acts, the use of condoms, and the number of partners. Even if we could determine the

117. This dependency arises from changes in the number of sexual partners individuals are inclined to have in light of overall sexual mores.

118. See generally Leishman, Heterosexuals and AIDS, Atlantic Monthly, Feb. 1987, at 37; The Revolution is Over, TIME, Apr. 9, 1984, at 74.

119. See generally Leishman, supra note 118; see also The Revolution is Over, supra note 118.

120. A. Kinsey, W. Pomeroy \& C. Martin, Sexual Behavior in the Human Male (1948).

121. Several studies have shown a relationship between food cue prominence and food-directed performance, especially among obese subjects. See, e.g., Schacter \& Friedman, The Effects of Work and Cue Prominence on Eating Behavior, in Obese Humans and Rats 11 (S. Schacter \& J. Rodin eds. 1974); Ross, Effects of Manipulating Salience of Food upon Consumption by Obese and Normal Eaters, in OBESE Humans and Rats, supra, at 43; Johnson, The Effects of Cue Prominence and Obesity on the Effort to Obtain Food, in Obese HUMANS AND RaTs, supra, at 53.

122. For example, what is the net effect on the rate of unwanted pregnancies?

123. For example, what are "healthy" or "moral" sexual attitudes or behaviors? 
impact of rampant sexual stimulation in print, in music, and on big and small screens, there would be substantial barriers to public action aimed at changing their content. The concerns of moralists and libertarians have dominated the censorship debates for years. The Supreme Court has repeatedly sided with the libertarians; ${ }^{124}$ television and radio are the only media where substantial censorship is allowed.125 Television is censored largely by the industry itself, often with perverse effects. There are an overwhelming number of sexual images and interludes on network television, but condom ads are largely banned as potentially offensive. ${ }^{126}$

Changing messages is not the only means of influencing sexual frequency. A strong body of laws and customs once existed to minimize extramarital frequency. Nosey hotel clerks, laws prohibiting premarital sex, adultery, open cohabitation, and so forth, were all fairly common at one time. Although their effectiveness has never been determined, these laws probably had some effect: Still, it is unlikely that these laws will be revived. Even if one were very willing to trade privacy and personal autonomy for epidemic control, that trade probably can be made on more favorable terms in other policy areas.

2. Reducing Specific Risk. The specific risks of male-to-female and female-tomale transmission depend on the mix of sex acts and the frequency of condom use. The presence of other sexually transmitted diseases may also matter.

Messages in the schools and mass media could affect knowledge and attitudes about safe and risky forms of contact and about the proper use of condoms and other barriers. Sex education in the schools might be a useful forum for education on reducing specific risk, and the Surgeon General and others have promoted it as such, ${ }^{127}$ but the content of sex education can vary greatly. Some moralists may worry that sex education involves the delivery of pro-sex messages to children, and it is certainly conceivable that some curricula may, on balance, have such an effect. Thus, attempts to reduce specific risks may interfere with attempts to reduce frequency.

Libertarians, who think information is always good, favor sex education but are nervous about teaching anything that looks like morality, because it will always be a particular morality. It is hard to see how broader technical knowledge and competence about how to avoid the sexual spread of disease could do harm in terms of epidemic control, but it is easy to foresee furious arguments about "value-free" sex education or about the mix of values to be promoted. What sort of sex education will produce sexual attitudes most consistent with minimizing HIV transmission is unknown, or at least disputed. There is some evidence that the mix of value-free information, scare messages, and negative exhortation that composed drug education in the

124. See L. Hurwitz, Historical Dictionary of Censorship in the U.S. at xIvi-lxiii (1985).

125. Id. at 31, 103-04.

126. Koop Urges TV Condom Ads to Fight AIDS, N.Y. Times, Feb. 11, 1987, at A1, col. 4.

127. U.S. Public Health Service, Surgeon General's Report on Acquired Immune DeficienCy SyndRome 5 (1987). 
1960's actually increased the use of illicit drugs among its audiences. In any case, the other consequences and principles at stake are important enough that the HIV-infection-minimizing sex education program is not necessarily the optimal education program overall.

Sex education need not be limited to youngsters. Adults could benefit greatly from increased knowledge of how to avoid infection. The extent of behavioral change required to stem HIV transmission is daunting, particularly in light of how unwilling much of the population has been to change smoking, eating, drinking, and exercise habits. Still, there is evidence that condom use increases following intensive education and information campaigns on its benefits. ${ }^{128}$

From the epidemic control viewpoint, the right mix of policies might involve increased sex education in the schools and government action to reduce the mass media's dose of messages in support of casual unprotected sex. Supporting both policies at once, however, requires a willingness to ignore or discount the potential side effects of such policies on other sexually transmitted diseases, unintended pregnancies, family structure, and cultural attitudes toward sex roles. Supporting both policies at once suggests a willingness to support or oppose the sexual counterrevolution opportunistically, as it happens to be good or bad for AIDS epidemic control, and to ignore or discount first amendment issues. Such willingness is not widely shared. Even if it were, the absence of data would prevent any consensus on policy.

3. Reducing Seropositive/Seronegative Contacts. The remaining option is to influence seropositive/seronegative contact patterns. This in turn could come either from a reduction in the number of sexual partners or from partner screening.

Reducing the number of partners reduces risk by reducing the chances of encountering at least one infected partner. It increases in importance as the product of the infection rate among potential partners and the specific risk per act rises.

Partner screening could involve personal judgment about likely risk factors, closed-circle AIDS-free clubs which attempt to combine the pleasures of variety with the safety of fidelity, or testing. As long as HIV risk is correlated with observable factors such as age and ethnicity, unassisted judgment will improve one's odds, but with substantial errors, both false positive and false negative. The clubs will presumably serve only a small minority and will face substantial compliance problems.

Testing is far more accurate than guessing and could serve a large population. If a serum status identification system were in place, couples could routinely check to see that potential partners were compatible. In the heterosexual population, such a system would allow the uninfected majority

128. N.A.S., supra note 1 , at 98. 
largely to disregard the threat of infection. This could lead to a decrease in safe sex and an increase in the average number of partners. However, given the inevitable leakage from false negatives and risky contacts, this risk compensating behavior might vitiate the benefits of an identification system.

An "HIV-free" identification system would tend to deprive infected heterosexuals of sexual opportunities except to the extent that seropositives were able to seek one another out. That effect seems desirable because an infected person's interest in having sexual opportunity is outweighed by the interests of the uninfected in remaining so. An identification system would greatly benefit minority group populations in some cities. In New York, for example, it is reasonable to think that seroprevalence among minority men aged 20 to 40 is high enough to confront minority females with some excruciating choices in the absence of any HIV status identification scheme.

4. Premarital Screening: A Special Case. Screening for HIV has been proposed as a condition of marriage in a number of states and has been endorsed by the President and the Secretary of Education. ${ }^{129}$ It is now law in Illinois and Louisiana. ${ }^{130}$ Such proposals, which intend to reduce the frequency of HIV transmission within marriage and the number of HIV-positive children born, have been attacked as illogical, oppressive, and impractical. From a viewpoint restricted to couples planning to marry, these labels are undeserved; premarital testing seems, under plausible assumptions, a reasonable investment, and there are strong arguments for making testing mandatory rather than relying on negotiations between each prospective bride and groom. From a broader viewpoint, however, premarital testing may be less desirable because it will tend to reduce the frequency of intramarital transmission only at the expense of increasing the frequency of extramarital transmission. ${ }^{131}$ The net effect remains unclear. ${ }^{132}$

Because both sex and procreation can and do occur outside the bond of marriage, preventing marriage does not necessarily prevent transmission of the virus. This observation, although logically correct, is not conclusive. The question is not whether the test will prevent all transmissions among tested couples or to children, only whether it will prevent some, and at what monetary and other costs. Again, the fact that in some couples transmission will already have occurred reduces the benefits of premarital testing without eliminating them. If the application for a marriage license is no more than a convenient and customary point at which the state can intervene, that may be reason enough to proceed if the benefits justify the cost.

129. Dewar \& Boodman, Reagan Favoring Testing for AIDS, Boston Globe, May 22, 1987, at 1, col. 4 .

130. Ill. Stat. Ann. ch. 40 ๆ 204(b) (Smith-Hurd Supp. 1988); La. Stat. Ann. \$§ 9:230(B), 231(B) (West Supp. 1988).

131. Mockler \& Kleiman, With This Test I Thee Wed: Evaluating Premarilal AIDS Testing, $7 \mathrm{~J}$. PoL. Analysis \& MGMt. 557, 560 (1988).

132. Id. at 560, 561 . 
It has also been argued that premarital screening is an unjustified invasion of the privacy and liberty of couples intending to marry. If either party is sufficiently concerned about his or her partner being infected, the argument goes, then he or she should insist on a test; why should the state intervene? To this there are four answers. First, as argued above, the transmission of HIV is not a matter of public indifference; if, as a result of a failure to test, one party in the marriage transmits HIV to the other or an infected child is born, not all of the costs will be borne by the couple involved. Second, a seropositive person who marries a seronegative person puts him or her at very substantial peril; a decision to marry in ignorance of infection is not one taken in the unconstrained exercise of personal freedom. If there is a clear moral duty to inform a potential sex partner of one's HIV status, why should the state not legally enforce that duty when it conveniently can? Third, the asymmetry in risk between the genders may combine with other asymmetries in the relationship to distort the results of premarital negotiation; women, as the chief potential beneficiaries, may be unable or unwilling to insist. Fourth, if testing were voluntary, insisting on a test at the point of marriage might be taken to indicate a lack of trust; more couples might be broken up by disputes about whether to take the test than would be by the test results.

Objections on grounds of liberty would be better justified if it were proposed that a positive HIV test be a bar to marriage, rather than merely a fact which must be revealed to the potential spouse. In any case, the fact that persons forbidden to marry could still have sex and conceive children would greatly limit the ability of such a law to prevent transmission.

The practical objections to mandatory premarital testing-the frequency of false positive results and the substantial financial cost per true detectionboth arise from the presumably low seroprevalence among persons intending to marry. If only 0.03 percent of couples intending to marry have at least one infected partner, then 24 percent of the reported "positive" results will be false. ${ }^{133}$ Thus, if tests were administered to each of the 1.9 million couples getting married in the United States each year, 1,000 couples would be correctly identified as involving an infected man and an uninfected woman. According to one estimate, the costs of such a program, including counseling for those testing positive and their partners, would total over $\$ 100$ million, or roughly $\$ 50$ per couple. ${ }^{134}$ This estimate assumes that all tested couples will also receive counseling about the meaning of the tests and about HIV transmission. If, instead, only couples in which one or both partners tested positive received counseling, per-couple costs (averaging the majority that receives testing only and the minority requiring counseling as well) would fall to about $\$ 15$.

133. The calculations are made in detail in Barry, supra note 54, at 263.

134. See Cleary, Barry, Mayer, Brandt, Gostin \& Fineberg, Compulsory Premarital Screening for the Human Immunodeficiency Virus, 258 J.A.M.A. 1757, 1760 (1987). See also M. Kleiman \& R. Mockler, Mandatory Pre-Marital AIDS Testing 4 (unpublished paper for Analytical Methods Seminar at Kennedy School of Government, Harvard University, Cambridge, Mass., Mar. 21, 1988). 
Under such assumptions, the benefits of the program to the marrying couples could easily cover its costs. Even if only 20 percent of the women involved avoided infection either by breaking off the engagement or practicing safe sex, the prevention of 200 infections at a cost of $\$ 100$ million represents a cost per prevented transmission of only $\$ 500,000$. The reader should consider whether he or she would voluntarily accept a one-in-one hundred risk of HIV infection for a payment of $\$ 5,000$.

Of course, a massive testing program would have nonmonetary costs, both to those incorrectly identified as being infected (and their potential spouses) and to those correctly identified who would have to live with the knowledge of infection and the fear of disease. There is no straightforward way to decide whether these outweigh the benefits of avoided transmissions. But if one had to act on behalf of all couples marrying, one might reasonably prefer mandatory testing either to no testing at all or to the difficulties of a voluntary system. However, the story does not end here.

Some couples with one infected partner will decide not to marry. Some of the infected partners in these couples will become sexually abstinent [or] restrict themselves to "safe" sex, thus avoiding transmission. But other persons [who are] told they are infected and whose intended spouses break off the engagement will not restrict themselves to safe sex; some will refuse even to use barrier contraception. For the unmarried, the total number of sexual partners presumably increases (relative to entering marriage), and the incentive to prevent the transmission of HIV decreases (assuming that there is a stronger commitment to a spouse than to one of a series of lovers). Testing in these cases will lead not only to dollar costs and broken marriages but also to an increased number of HIV infections.

Whether these additional transmissions would outnumber the intra-marital transmissions prevented by testing cannot be estimated from any data now on hand. (It may even depend upon the nature and quality of the counseling services offered in conjunction with testing, a point which re-emphasizes the importance of counseling as part of any testing program.) Without better knowledge of the likely behavior of the tested positives, there is no way to tell whether premarital testing is a good idea or a bad one. ${ }^{135}$

In the absence of any convincing argument that premarital testing would produce a net reduction in the number of HIV transmissions, the strongest argument for it would involve the importance of the institution of marriage generally in social life and specifically in the control of the AIDS epidemic. In effect, one would have to argue that intramarital transmissions are even more undesirable than extramarital transmissions.

5. Politics and Obstacles to Change. Moralists have a strong stake in reducing premarital and extramarital sexual frequency and the number of sexual partners. Moralists can point to increasing rates of STDs, of teenage pregnancy, and of one parent families as costs of loosening the connection between coitus and marriage. Thus, reducing specific risk by distributing condoms, for example, does not appeal to moralists, and an HIV card might strike them as a government issued license to practice fornication.

135. Mockler \& Kleiman, supra note 131, at 560, 561 . 
Libertarians have a string of victories to protect in the areas of sexual behavior and censorship. AIDS makes it more difficult to insist that sexual behavior, even among consenting adults, is of only private concern or that private voluntary action will always adequately control its own side effects. To the extent that voluntary HIV-free cards would detach sexual behavior from public concern, they further the libertarian agenda. Furthermore, cards could stiffen resistance to demands for more drastic forms of isolation of seropositives.

Following this path would divide libertarians from their allies in the gayrights movement, because testing would threaten gay solidarity by dividing the infected from the uninfected. It would also show the falsehood of the slogan, "No risk groups, only risky acts." Moreover, it would free most heterosexuals from the changes in sexual behavior being forced on homosexual men by the epidemic.

\section{Heterosexual Prostitution}

Compared to noncommercial heterosexual congress, prostitution poses special threats and may be amenable to special strategies. Many female prostitutes are IV drug abusers; ${ }^{136}$ most also face some occupational risk of HIV infection. Prostitutes expose their partners to possible infection and risk infection themselves. Calculating the annual number of HIV infections likely to stem from prostitution is difficult and requires estimates of several variables which are only poorly known. ${ }^{137}$ Rough calculations suggest that between 500 and 5000 men and 250 to 2500 women will become infected with HIV this year as a direct result of paid male-female sexual contact in the United States. ${ }^{138}$ These infections will lead to some unknown number of secondary infections among prostitutes' and customers' noncommercial sexual partners and tertiary infections among those partners' other sexual partners and children.

Although the spread of HIV via prostitution will only slightly increase the total number of infections, it is well worth controlling. The number of prostitution related transmissions is a function of the frequency of prostitution transactions, the riskiness of those transactions to prostitutes and customers, and the number of transactions involving one uninfected and one infected party. Public authorities can influence these three factors with messages aimed at inducing voluntary change and laws designed to force change.

136. P. Goldstein, Prostitution and Drugs 92-95, 145 (1979) (however, this abuse is concentrated in streetwalkers); L. Clarke, Reducing the Transmission of AIDS Via Prostitution: A Policy for the Massachusetts Department of Public Health 5-12 (John F. Kennedy School of Government, Harvard University, unpublished Master's Thesis, Apr. 21, 1987).

137. Such variables include the specific risk of different sexual acts and the total annual number of prostitution transactions in the United States.

138. M. Kleiman \& R. Mockler, AIDS and the Criminal Justice System: Developing a Policy Agenda 14 (Program in Criminal Justice Policy and Management, John F. Kennedy School of Government, Harvard University, Working Paper No. 87-04-01, 1987). 
1. Changing the Frequency of Prostitute Contacts. The total number of prostitution transactions could be reduced through negative advertising modeled after the anti-tobacco TV campaign of the late 1960's. The content of such advertisements should be based upon market research about the attitudes of prostitutes' customers. A number of themes suggest themselves: advertisements might emphasize disease risk, or they might suggest that prostitutes' customers are ridiculous or unmasculine.

On the supply side, voluntary and confidential HIV testing and counseling for prostitutes might reduce the number of practicing prostitutes. Uninfected prostitutes might leave the trade if they became convinced that continued practice put them at risk. This would have two conflicting effects. To the extent that uninfected prostitutes leave the trade, the supply of prostitutes' services and the number of prostitutes infected by customers will be reduced. But an increased quit rate among uninfected prostitutes would tend to increase the seroprevalence among the remaining active group. Encouraging infected prostitutes to leave the trade would have only good effects: both a reduction in the supply of prostitutes' services and a reduction in the seroprevalence among active prostitutes.

Since prostitution is illegal nearly everywhere in the United States, law enforcement can also be used to reduce the number of prostitution transactions. Historically, prostitution enforcement has been aimed at keeping the trade geographically confined and out of sight. ${ }^{139}$ AIDS increases the value of actually shrinking the prostitution industry. Police could enforce current laws more vigorously by increasing attention and arrests for the less blatant forms of prostitution such as massage parlors and escort services. Clarke suggests that these "sex industry" enterprises are likely to account for many more HIV transmissions than are due to streetwalkers. ${ }^{140}$

Police could also pressure customers by arresting them and publicizing their names. This policy might noticeably decrease the demand for prostitutes' services, particularly if the publicity referred to patronizing the prostitutes as part of the AIDS problem. The effectiveness of such a program would depend largely on the composition of the customer population, something about which we currently know very little. If, as Reuter suggests, much of the market is made up of "young, unmarried and unattractive males," such measures would have a much smaller impact than if the market consists more of married men. ${ }^{141}$

2. Reducing the Riskiness of Contacts. The specific risk of the average prostitute-customer contact could also be changed by a campaign of information and persuasion aimed at changing the mix of sexual acts involved or by increasing the use of condoms. However, because prostitution remains

139. See H. Reynolds, The Economics of Prostitution 40-42 (1986); see also B. Cohen, Deviant Street Networks 71-72, $117-21$ (1980) [hereinafter Deviant StreEt Networks].

140. L. Clarke, supra note 136, at 9-10.

141. Interview with Peter Reuter, Economist, Rand Corporation (Aug. 1987). 
illegal, any public agency which sponsored such publicity would be in the uncomfortable position of counseling citizens on how to break the law safely.

Messages could be aimed at both customers and prostitutes. Those prostitutes who know that they are uninfected have an incentive to practice safe sex; their interests coincide with everyone else's. Clarke found in interviews that many Boston prostitutes were aware of AIDS and wished to avoid it but were often coerced physically or financially by customers or pimps into risky acts. ${ }^{142}$ Many prostitutes felt their livelihood depended on risky acts. ${ }^{143}$

It also would be desirable for anti-prostitution law enforcement efforts to distinguish risky acts from safe acts, but doing so would require police to go much further toward completing transactions than is now permitted in this country. ${ }^{144}$ In addition to its expense in police time, such practices would give entirely new and unsavory meaning to the phrase "undercover activity."

3. Reducing Seropositive/Seronegative Contacts. A customer's chances of encountering an infected prostitute depend on the (frequency-weighted) seroprevalence among active prostitutes. Absent any sort of identification method, this in turn depends on: (1) the proportion of prostitutes who are intravenous drug users and who become infected (before or after becoming prostitutes) by needle sharing; (2) the proportion infected by customers or noncommercial sexual partners; and (3) the rate at which infected prostitutes leave the trade.

One way to reduce the number of active prostitutes infected through needle sharing is to crack down on retail heroin sales. ${ }^{145}$ A second is to offer drug treatment programs to reduce the economic pressure that makes it difficult for heroin using prostitutes to leave the trade, although prostitution may remain the most economically attractive calling for many heroin using prostitutes even once their drug habits are under control.

Prostitutes who are currently infected and know it face a different set of choices than do uninfected prostitutes. It is not clear that the interests of infected prostitutes run with the public interest. Infected prostitutes need no longer fear HIV infection. However, they might quit the trade if they were convinced that exposure to semen and to sexually transmitted pathogens increased their probability of becoming ill with AIDS or ARC, ${ }^{146}$ or if they felt some responsibility not to transmit the virus. The private benefits of leaving the trade or adopting more cautious practices may not outweigh the private costs. A testing and counseling program which inadvertently encouraged uninfected prostitutes to quit and infected prostitutes to continue practicing

142. L. Clarke, supra note 136 , at 9,11 .

143. Id. at 9 .

144. Recent news reports indicate this is now occurring in Europe. Shearer, The Condom Cops,

Parade Magazine, Aug. 2, 1987, at 10.

145. See infra at (MS 75).

146. N.A.S., supra note 1 , at 57 (suggests that pregnancy might increase this probability). 
would increase the seroprevalence among practicing prositutes, putting customers at a greater risk than before.

Given the danger which infected prostitutes pose to their customers, an argument can be made for social programs to induce prostitutes to stop practicing. However, infected women could enter the trade to obtain eligibility to participate in the programs. If this occurred, the financial costs of the programs would increase with the increased volume of participants and the benefit in terms of AIDS control would be reduced or even reversed, since the new entrants would presumably practice for some time before being eligible for enrollment. The greater the proportion of female HIV carriers who are already prostitutes, the less important this perverse incentive would be.

Mandatory testing is another approach. This could be done either in the current environment of illegal prostitution or as part of the regulation of a legalized prostitution industry. If prostitution were legal, frequent screening and license revocation for seropositives could keep the infection rate among prostitutes to a fraction of 1 percent. ${ }^{147}$ Customers would be on notice that contact with unlicensed prostitutes was particularly risky. Such a scheme would be effective only if regulation were well-enforced and focused primarily on disease, with prostitutes losing their licenses only for testing positive for HIV or other STD's. If regulation were poorly enforced, licensed prostitutes could be carriers. If licenses were revoked for reasons other than HIV infection, then customers would not presume that unlicensed prostitutes were infected and an illicit market could develop alongside the licit one as is the case in Germany.

As long as prostitution remains illegal, screening must be infrequent and sporadic. Still, prostitutes, particularly the drug dependent prostitutes who are most likely to be infected, are arrested rather frequently. ${ }^{148}$ If persons convicted of prostitution or narcotics possession were routinely tested for the virus, a large proportion of infected street prostitutes would be identified within one year. ${ }^{149}$ Practicing prostitution after testing positive could subject the offender to criminal sanctions or to isolation ordered by the public health authorities.

It is difficult to predict risk compensating behavior with respect to legalization or testing. To the extent that prostitutes' potential customers are deterred by the threat of AIDS, any reduction in the perceived seroprevalence among prostitutes could increase demand for their services or decrease

147. None of the 34 Nevada prostitutes tested by the Centers for Disease Control were HIVpositive. See Centers for Disease Control, Antibody to Human Immunodeficiency Virus in Female Prostitutes, 36 MORBIDITY \& MORTALITY WEekLY ReP. 157, 158 (1987) [hereinafter Antibody to HIV].

148. Cf. P. Goldstein, supra note 136 , at 89 (drug dependent prostitutes face a high probability of being arrested).

149. The seroprevalence among prostitutes would keep the relative frequency of false positives low, even with current testing technology. 
condom use by customers. ${ }^{150}$ If demand were highly sensitive to perceived risk, or if perceived risk fell faster than actual risk, a program to screen out seropositive prostitutes could have perverse effects. Protecting customers from infected prostitutes is much easier than protecting prostitutes from infected customers; hiring a prostitute is presumably more spontaneous and irregular than working as a prostitute, and the creation of time consuming onthe-spot testing requirements might create demand for an unregulated parallel market. In a legal market without regulation of risky acts, customers might refuse to use condoms or practice safe sex, thus placing prostitutes at greater risk of infection.

The widespread use of a serum status identification scheme would simplify the control of prostitution related HIV transmission. Regardless of prostitution's legal status, customers could protect themselves from infected prostitutes, and prostitutes could protect themselves from infected customers. Market pressure could drive uninfected prostitutes to acquire the identification and eventually force infected prostitutes out of business. An interest in self-protection would encourage uninfected prostitutes to require identification of customers, and uninfected customers would have incentive to comply.

4. A Policy of Paralysis. In the absence of an identification system, it seems plausible that either legalization (with screening) or a vigorous enforcement crackdown (with screening) would reduce transmissions when compared with the current regime of weakly enforced prohibition without testing plus some education and counseling. Yet neither legalization nor vigorous enforcement has yet been even a serious topic of public debate. Why not?

Consider first the crackdown. Police do not like arresting hookers; police like to think they have better things to do. Prosecutors and judges do not like handling the cases, which are routinely pled out and draw small fines, further discouraging the police. ${ }^{151}$ Even those who think that prostitution is evil, from a moralist or feminist perspective, find it hard to work up much indignation against prostitutes, and this makes a program of punishing them and depriving them of their livelihood unattractive, particularly when a shortage of jail and prison cells means that imprisoning prostitutes would require freeing other wrongdoers. ${ }^{152}$ Additionally, "johns" command little sympathy; there may be some sense that they are getting just what they asked for if they happen to acquire HIV. More vigorous enforcement against customers and pimps is the one part of the crackdown prescription likely to

150. There is anecdotal evidence that demand for prostitution has declined in the face of the AIDS epidemic. Fear of AIDS Chills Sex Industry, U.S. NewS \& WORLD ReP., Feb. 16, 1987, at 25; see also Leishman, supra note 118.

151. Deviant Street Networks, supra note 139, at 155.

152. Crimes such as prostitution are perfect candidates for non-prison "alternative" punishments, but in the corrections system the shortage of alternatives exceeds even the shortage of cells. 
appeal to moralists and feminists alike. Targeting customers and pimps is also almost certainly the best way to attack juvenile prostitution.

The libertarian view is that prostitution ought to be legal and that enforcing prohibition is morally wrong, because it punishes an innocuous act, reinforces the governmental habit of meddling where it does not belong, and retards private risk-control measures. ${ }^{153}$ The investigative techniques required for prostitution enforcement are intrusive and create great temptations for perjury, corruption, and police violations of the law. ${ }^{154}$ Libertarians may oppose compulsory screening of prostitutes on its own merits; in addition, they may fear such programs could set a precedent for testing food service workers, immigrants, and other groups for whom screening would have no epidemic control benefits.

Legalization fits the libertarian view perfectly, and some would concede the necessity of licensure and screening as adjuncts. However, libertarians do not rank legalization of prostitution as a high priority target among all the battles in which the new moralism has them engaged.

Moralists and some feminists argue that legal prostitution would be worse than illegal prostitution even if its measurable consequences were better, because the state sanctions would multiply the effectiveness of the bad messages conveyed by the fact of prostitution. Moreover, the recent U.S. history of legalized vice, alcohol, and gambling suggests that legalization leads to vigorous promotion. The economic interests of producers and the taxing authority are aligned together against tight controls. ${ }^{155}$ As long as lawyers can persuade courts to seriously consider the proposition that because tobacco is not strictly forbidden, the first amendment precludes any attempt to regulate tobacco advertisements, the practical case for legalized and regulated vice remains in doubt.

\section{Male Homosexual Contact}

In the United States, HIV spread first and fastest among homosexual men. Rates and modes of infection and response to the epidemic have been much different among this group than elsewhere. The initial identification of AIDS as a "gay plague" greatly influenced the response of other groups to the disease. ${ }^{156}$ The disease has merely reinforced some moralists' abhorrence of homosexuality and provided an excuse to renew calls for its suppression. ${ }^{157}$ Norman Podhoretz characterized the search for an AIDS vaccine as an

153. See H. Reynolds, supra note 139, at 190-91. See generally G. Geis, Not the LAw's Business 173-221, 251-62 (1979).

154. H. Benjamin \& R. Masters, Prostitution and Morality $372-73$ (1964) (list of criticisms of the prohibitionist approach in the United States). See also H. Reynolds, supra note 139, at 181-96.

155. R. King, Gambling and Organized Crime 166-69 (1978); Bahmueller, State Policy and the Ethics of Gambling, in Commission on the Review of the National Policy Toward Gambling, Gambling in America 745, 768-69 (1976).

156. See R. Shilts, supra note 71 , at xxii; see generally D. Altman, AIDS in the Mind of America (1986).

157. Cleric Says Existence of AIDS Shows God Unhappy with Homosexuality, Associated Press International Wire Service, Jan. 17, 1986. 
attempt to allow gays "to resume buggering each by the hundreds with complete medical impunity."158 Libertarians and gay-rights groups, acutely aware of the potential for repression implicit in identification of the disease with homosexuality, have sometimes seemed to subordinate public health concerns to civil liberties concerns: "Ultimately, it may be more important to let people die in the pursuit of their own happiness than to limit personal freedom by regulating risk." 159 The strong ideological commitment on both sides tends to devalue arguments concerned with slowing the spread of disease among homosexual men and from them to others.

In some areas, seroprevalence among homosexual men who have had large numbers of sexual partners approaches 50 percent. ${ }^{160}$ The high prevalence indicates a high probability that a sexual partner who is a male homosexual or bisexual will be infected. The absolute number of infected male homosexuals is much higher than the number of infected heterosexuals; homosexual men still account for 85 percent of all cases. ${ }^{161}$

Although research on the sexual behavior of homosexuals is as scarce as that on heterosexuals, it appears that the sexual habits of many homosexual men also place them at a higher risk than heterosexuals. ${ }^{162}$ Risky sexual acts, such as anal intercourse, seem to be more common among homosexual men than among heterosexuals, although self-reports indicate major shifts toward safer sex by homosexual men. ${ }^{163}$ Homosexual men also appear to average more sexual partners over a lifetime than male heterosexuals. ${ }^{164}$ The combination of high prevalence, high specific risks, and many partners has produced high infection rates. ${ }^{165}$

Another important difference between homosexual men and heterosexuals is the high degree of community solidarity which homosexual men, at least openly homosexual men in urban areas, have built. ${ }^{166}$ This solidarity has proven invaluable both in caring for the sick and in spreading safe sexual practices. The large and politically powerful gay community in San Francisco is widely given credit for that city's innovative management of the AIDS

158. Podhoretz, AIDS in Plain English, The N.Y. Post, Sept. 4, 1986, at 27.

159. Callen \& Berkowitz, We Know Who We Are, in The New York Native 29 (1982), quoted in D. AltMan, supra note 156 , at 146.

160. N.A.S., supra note 1 , at 89 .

161. Id.

162. Marmor, El-Sadr, Zella-Pazner, Lazaro, Stahl \& William, Immunologic Abnormalities Among Male Homosexuals in New York City: Changes in Time, in Acquired Immune Deficiency Syndrome 312,317 18 (1984).

163. See Centers for Disease Control, Self-Reported Changes in Sexual Behaviors Among Homosexual and Bisexual Men from the San Francisco City Clinic Cohort, 36 Morbidity \& Mortality Weekly Rep. 187. 187-89 (1987) [hereinafter Self-Reported Change]; Spread of AIDS Infection in U.S. May be Slowing, Studies Indicate, Wall Street J., May 18, 1987, at 8, col. 5 (Eastern ed.).

164. A. Bell \& M. Weinberg, Homosexualities 82 (1978).

165. N.A.S., supra note 1 , at 7,89 (Seropositivity among male homosexuals may range from under $20 \%$ for populations including any individual who has participated in homosexual activity to over $50 \%$ in areas for men who have had many partners; in some cities, as many as $70 \%$ may be infected.).

166. See generally D. Altman, supra note 156, at 81-109. 
health care delivery system. ${ }^{167}$ Gay organizations have encouraged the trends toward fewer partners, condom use, and nonpenetrative "safe sex."

Some men who regularly have sex with other men also have female sexual partners-some on a casual basis, some because they are married. ${ }^{168}$ These women are at risk of acquiring HIV, although the vast majority of women sexually infected with HIV had IV-drug-using, rather than bisexual, partners. ${ }^{169}$ Complicating the situation are factors such as the likelihood that married men who have homosexual contacts will not be identified members of the gay community; these men will not have access to the educational resources of that community and may be more likely to practice unsafe sex and less likely to form long term mutually faithful homosexual relationships. ${ }^{170}$

The differences between homosexual and heterosexual men in the AIDS epidemic profile make different strategies necessary with respect to the two groups for slowing the spread of HIV and protecting the interests of both the uninfected and the infected. Currently, uninfected homosexual men who practice unprotected penetrative sex face a much higher risk of infection than does virtually anyone else except intravenous drug users. To protect themselves, homosexual men will have to make drastic changes in behavior with regard to number and selection of partners and the riskiness of their sexual acts. Recent changes in the sexual behavior of homosexual men in some cities have been in the direction of reduced risk, but these changes have occurred discouragingly slowly in areas where current seroprevalence is relatively low. ${ }^{171}$

Among heterosexuals, the institution of marriage has been held out as a powerful barrier against the transmission of HIV. Insofar as marriage reduces the overall number of sexual partners and creates very strong incentives for partners to discover their relative HIV status and act accordingly, it will tend to reduce the number of transmissions. In the absence of needle sharing, "Chastity before marriage, fidelity after" is, if mutually observed, a formula for complete safety with respect to AIDS.

The argument for marriage as an AIDS prevention device would seem to be equally valid for homosexuals, and with much greater effect in terms of the number of potential transmissions prevented. The trend towards fewer

167. Hamilton, Volunteers, Home Care and Money: How San Francisco Has Mobilized, Business WEEK, Mar. 23, 1987, at 125; see also R. Shilts, supra note 71, at 394-95, 569-70.

168. Hamilton, supra note 167 , at 125 ; see also A. Bell \& M. WeinBerc, supra note 164, at 160-61.

169. See N.A.S., supra note 1 , at 90 .

170. Id. at 101; 4 New York Bath Houses Still Operate Under City's Program of Inspections, N.Y. Times, May 3, 1987, $\S 1$, at 58, col. I (quoting Raymond M. Jacobs, coordinator of AIDS Prevention at the Gay Men's Health Crisis).

171. See, e.g., Fleming, Cochi, Steece \& Hull, Acquired Immunodeficiency Syndrome in Low Incidence Areas, 258 J.A.M.A. 785, 787 (1987) ("Unprotected sexual activity may still be the norm for many gay and bisexual men in New Mexico. A survey of gay men in Albuquerque indicated that $76 \%$ were practicing receptive anal intercourse and only $10 \%$ were using condoms more than $10 \%$ of the time.") (citing Jones, Waskin, Gerety, Skipper, Hull \& Mertz, Persistence of High-Risk Sexual Activity Among Homosexual Men in an Area of Low Incidence of the Acquired Immunodeficiency Syndrome, 14 SEXUALLY Transmitted Diseases 79, 80 (1987)). 
partners and a safer mix of sex acts among homosexual men might be accelerated if gay couples could have their promises of mutual fidelity solemnized legally and if they then counted as "married" for purposes of insurance, inheritance, pension rights, credit, and so on. However, the stampede of support for "gay marriage" bills from those who believe that (heterosexual) marriage is the best protection against AIDS has yet to develop.

Even if the frequency and specific risk of sexual contact among homosexually active men did not change, the total number of HIV transmissions due to homosexual activity could change if the number of active male homosexuals increased or decreased. Merely to raise the topic of how public or private actions might influence that number is to tread on dangerous ground; the sensitivity of AIDS as a policy issue is due very largely to its connection with this question. Supporters of gay liberation fear, and their opponents hope, that AIDS will provide a pretext for rolling back the progress that has been made toward state and social neutrality on matters of sexual preference and its expression. The spread of HIV offers the clearest possible challenge to the doctrine that what "consenting adults" do in bed is nobody else's business. However, ignoring that challenge will not make it disappear.

Just as it does not follow that what someone conceives to be morally offensive is therefore socially dangerous, it does not follow that whatever is morally neutral is therefore socially benign. Even if trends among homosexual men toward safer sex and fewer partners went so far that homosexual risk per act and mean number of partners matched heterosexual levels, the very high HIV seroprevalence among the currently active male homosexual population would leave the currently uninfected proportion of that population at far higher risk than their heterosexual counterparts. Men who have sex with men will have to practice much safer sex with many fewer partners to reduce their HIV infection risk to the level of men who have sex with women.

Thus, the number of men who become homosexually active at some time in their lives is important from the perspective of AIDS control. But it is far from clear what, if anything, can be done on a practical level to influence that number. The extent to which sexual preference and its expression are voluntary rather than being determined by some combination of genetics and early environment remains hotly disputed, although, if adolescent and young adult experimentation is taken into account, it seems hard to believe that voluntary choice is never involved. Those making such choices ought to be in possession of the facts. Also, in the service of two worthy objectivesencouraging heterosexuals to practice safe sex and discouraging the expression of anti-homosexual bigotry-there has been some tendency to downplay the special risks of sex among men. ${ }^{172}$

172. For example, the author found the following passage in a brochure which he picked up at a Lutheran Church in Cambridge, Massachusetts: 
Thus, there are substantial roadblocks to achieving the enormous changes in frequency, specific risk, and rate of partner switching required to give currently uninfected homosexual men a normal life expectancy. The only remaining option is to reduce the proportion of male homosexual contacts that cross the seropositivity line.

A properly designed serum status identification system such as the one described in part I could be of enormous advantage to homosexual men. By far the most important question between prospective sexual partners is whether or not their serum status is the same. By answering that very question, a "red light/green light" system could drastically reduce the relevance of population prevalence and number of partners. By giving infected individuals a community sanctioned way of confidentially identifying one another, the system could provide them with access to sexual expression.

Such a system would not be perfect, of course. Testing errors will always occur; the higher population seroprevalence among homosexual men would lead to a larger proportion of false negatives. ${ }^{173}$ This would mean that the seroprevalence among those testing negative would be above zero, but it would still be far below that of the untested population. ${ }^{174}$ The problem of false positives becoming infected through contact with true positives would be small compared with the current infection rate. A card system would not bring the risks of male homosexual activity down to those of heterosexual activity, but it would substantially narrow the gap.

Other potential complications of a card system include an increase in other sexually transmitted diseases due to risk compensating increases in frequency and decreases in the practice of safe sex. ${ }^{175}$ Infected individuals probably still would have an interest in safe sex, at least until it is determined what roles reinfection and exposure (to other pathogens and foreign proteins) play in disease expression. Given the high seroprevalence among male homosexuals, the high specific risks of many sexual acts between men, and the improbability

During discussions about AIDS with preteens and teens, the subject of homosexuality may come up. It is true that so far nearly three out of four people with AIDS in this country have been gay or bisexual men. But the opposite is true in other parts of the world. Anyone, gay or straight, can get AIDS if they have intercourse with an infected person. An increasing number of nondrug-using heterosexuals in the U.S. have been diagnosed with AIDS.

If you want to explain to your child what homosexuality is, you may simply say that just as men and women may love each other in a special way, so do men sometimes love other men, and women sometimes love other women. You may tell your children that you are neither condeming nor encouraging this kind of loving.

To condemn a group of people because of sexual orientation may be to unknowingly condemn neighbors, friends, or family members.

Talking to Your Family about AIDS, Family Resources Brochure \#24, Division of Parish Services, Lutheran Church in AMERICa 6 (1987) (Information regarding this brochure is available from Editor of Family Resources, DPS, 2900 Queen Lane, Philadelphia, PA 19129.).

173. Barry, supra note 54, at 263, 266.

174. Among a population with $50 \%$ seroprevalence, even a test with sensitivity and specificity equal to $99.7 \%$ would have three false negatives in every group of 1000 true negatives, for a seroprevalence among negative testees of $0.3 \%$.

175. This would also be affected by the permanency of the behavioral changes already made by gay men. 
of complete monogamy in any population, it might be necessary to combine a move toward nonpenetrative sex, condom use, a reduction in the number of partners, and a card system in order to reduce lifetime personal risks to even minimally tolerable levels.

Opposition to testing among libertarians and gay-rights groups has focused on potential discrimination against the infected and on potential harm to solidarity within the homosexual community. The system discussed here would leave little room for discrimination, since test results would not be recorded by name and any sharing of these results would require consent. Community solidarity would be crucial for this scheme's success. By providing safety and sexual opportunity to both the infected and the uninfected, the system could also serve to lessen fear and distrust among homosexual men. It would have the added benefit of undercutting the arguments for suppressing homosexuality.

While an identification system could provide great benefit to identified homosexuals, its usefulness in keeping HIV from spreading to other populations is less certain. If the system did keep down the seroprevalence among homosexual men, it would also keep down the risk among their other partners. However, unless use of the system became widespread among heterosexuals also, the effects on the partners of bisexual men, including those who are married and secretly bisexual, could be perverse. It is conceivable that infected and identified individuals could look outside the homosexual community for partners at a higher rate than they otherwise would. With no system in place among heterosexuals, both women and secretly homosexual men might then face a higher risk of infection.

All these problems are important, but none overwhelms the advantages such a program could have in preserving lives of gay men. Risk compensation among the uninfected would be a problem, but the remaining lifetime risks would be high enough to encourage caution, particularly if it were backed by continued "safe sex" messages from gay health groups.

Funding should not be an obstacle to a card system. The costs of HIV infection are large enough to justify public funding of such a program. Whether funding would be forthcoming is a different question. In its absence, however, the private interests of homosexual men in their own health and sexual freedom would probably support a system provided through some market or quasi-market arrangement, ${ }^{176}$ especially in large urban areas. Health insurers would have strong incentives to subsidize such a program. Given the number of lives at stake, all of these options seem worth exploring, but the anti-testing commitment of the gay leadership seems to be an almost insurmountable barrier.

176. Such a quasi-market arrangement would involve a non-profit organization. 


\section{E. Intravenous Drug Abuse}

People who inject themselves with illicit drugs, primarily heroin users, spread AIDS among themselves by sharing unsterilized needles. ${ }^{177}$ Some drug users then carry the virus into the nonuser population by giving it to their sexual partners, who carry it further to other sexual partners and to children. Most AIDS among prostitutes stems directly from their own IV drug use, and most newborn pediatric AIDS cases stem from one or both parents' use of IV drugs. ${ }^{178}$

1. Reducing Frequency. Both stepped-up enforcement and increased availability of treatment programs could reduce the frequency of IV drug use.

Increased enforcement, by making heroin either more expensive or harder to find, should tend to decrease heroin use just as higher cigarette taxes tend to decrease tobacco use. Street level crackdowns have reduced overall levels of heroin use in some areas, ${ }^{179}$ and such programs probably have dramatic effects on the recruitment of new users, which seems to vary sharply with retail market conditions. ${ }^{180}$

Expanding treatment programs could reduce the incidence of AIDS among heroin users. ${ }^{181}$ Such an expansion could assist those who participate in treatment programs, regardless of their HIV status. However, the value of more treatment in reducing the spread of HIV is less certain. Expanded treatment could lower the overall frequency of heroin use, but it might do so with perverse consequences for remaining users. ${ }^{182}$ In areas where recruitment of new users is high, treatment would be valuable if it could be targeted at those new users who have yet to become infected. However, that would require a major change in current treatment patterns: Some methadone clinics now require a two year history of drug use for admission to ensure that nonaddicts are not using methadone clinics as sources of drugs. ${ }^{183}$

Thus, "expanding treatment" requires changing the nature of treatment as well as spending more money. Moreover, because trained treatment personnel are scarce, rapidly expanding methadone treatment programs probably would require shifting away from the current "therapeutic"

177. N.A.S., supra note 1 , at 6.

178. Antibody to HIV, supra note 147 , at 159; N.A.S., supra note 1 , at 62.

179. For general comments on street level crackdowns and some selected case studies, see $M$. Kleiman, Crackdowns: The Effects of Intensive Enforcement on Retail Heroin Dealing (Program in Criminal Justice Policy and Management, John F. Kennedy School of Government, Harvard University, Working Paper No. 87-01-11, December 1987).

180. M. Moore, Buy and Bust 24 I-47 (1975); Moore, Policies to Achieve Discrimination on the Effective Price of Heroin, 63 Am. ECON. Rev. 270, 272-73 (1973).

181. N.A.S., supra note 1 , at 108-09.

182. See section 3, Changing Conlact Patterns, infra (MS 78).

183. See, e.g., F. Hofmann, A Handbook on Druc \& Alcohol Abuse 279 (1983) (discussing "the prototype of most programs, that of Nyswander and Dole") (citing generally Dole, Nyswander \& Warner, Successful Treatment of 750 Criminal Addicts, 206 J.A.M.A. 2708 (1968)); see also J. Platt, Heroin Addiction Theory Research \& Treatment 309 (1986) (discussing the program of Nyswander and Dole). 
emphasis to simple drug maintenance. ${ }^{184}$ Given the possibly catastrophic consequences of even temporary relapses into heroin use, there would also be an argument for eliminating current limits on the length of treatment. Moreover, methadone "leaks" from clinics into street markets, where it is sold and injected much like heroin. ${ }^{185}$ This leakage from staff and clients would grow with the growth of the programs. Increased leakage would increase the availability of drugs to new users and thus tend to defeat the frequency reduction accomplished by the expanded treatment. Convincing potential recruits not to begin using heroin would be an ideal way to slow the spread of HIV to new users, but the efficacy of prevention campaigns has yet to be demonstrated.

2. Reducing Specific Risk. A variety of government actions could reduce the specific risk in IV drug use. Legalization of heroin-with the drug marketed or otherwise distributed in pre-filled, single dose disposable syringes-would almost eliminate the specific risk of HIV infection to users but would also increase the frequency of use, perhaps dramatically. The combined effect of legalization and increased consumption on crime, community life, the life chances of poor children, and public health and morals could be profound, for good or bad, and are not easily predicted. ${ }^{186}$ Legalization for current addicts only-heroin maintenance-is similar to expanded methadone treatment in its promise and perils.

Legalizing needles would have much less clear effects. Users probably would share less if needles were readily and legally available, but there is also evidence that in the heroin using culture, needle sharing has social values independent of its practicality. ${ }^{187}$ Making needles easier to get could lead some persons who currently smoke, swallow, or snort drugs other than heroin to begin to use them intravenously, even if it did not dramatically lower the barriers to heroin use per se. This would increase those persons' risk of acquiring AIDS and other ill effects of IV drug use.

Information could also serve as a reasonable substitute for new needles. Users can kill the AIDS virus with relatively simple sterilization procedures such as immersion in bleach, and informing users of these procedures would be simple and have few negative side effects. ${ }^{188}$ Exchanging new needles for old ones has limited direct value, because it would not relieve the scarcity of needles ${ }^{189}$ and because the relevant characteristic of needles is their being shared rather than being old. The offer of "clean needles," however, could be

184. For a discussion of therapeutic treatment, see Friedman, DesJarlais \& Goldsmith, $A n$ Overview of Current AIDS Prevention Efforts Aimed at Intravenous Drug Users, J. Drug Issues (forthcoming 1989).

185. B. Johnson, P. Goldstein, E. Preble, J. Schmeidler, D. Lipton, B. Spurt \& T. Miller, Taking Care of Business: The Economics of Crime by Heroin Abusers 4 (1985).

186. J. Kaplan, The Hardest Drug: Heroin and Public Policy 111 (1983) ("[P]redictions are quite uncertain and difficult.").

187. Friedman, DesJarlais \& Sotheran, supra note 18 , at 385.

188. Id. at 388 .

189. This assumes that scarcity is a factor promoting needle sharing. 
an inducement for users to meet with health workers who could distribute advice, and bleach, as they traded new works for old.

3. Changing Contact Patterms. Under limited circumstances, expanded treatment also holds some promise for reducing seroprevalence among users, thus reducing the chance that an uninfected user will encounter an infected one. To succeed, expanded treatment would have to substantially diminish the ratio of infected experienced users to recruits. Seasoned users are both more likely to be infected with HIV and more likely to enter treatment, but if seroprevalence in an area is already very high, many less experienced users will also be infected. Thus, the outflow of infected users into treatment programs might not significantly lower the seroprevalence among remaining users. However, in areas with relatively low seroprevalence, a program of expanded treatment for seasoned users might succeed in significantly lowering the seroprevalence of the remaining needle sharing population. In some areas far from New York, the prevalence of seropositivity among active heroin users may be as low as 2 percent. ${ }^{190}$

In addition to generalized street level crackdowns, police could target "shooting galleries," where users gather to shoot up and often to rent "works."191 By eliminating a common needle sharing environment, this targeting would tend to reduce the number of persons with whom any one person shares needles. In needle sharing as in sex, having few partners is safer than having many, particularly when seroprevalence is low. Arresting users for possession of needles should be abandoned because this tactic does little to counter drug use and provides users with an incentive to congregate in shooting galleries and share needles to avoid carrying contraband. Though testing drug using prostitutes might help to protect their customers, it is difficult to conceive of an effective screening or segregation policy to protect drug users from each other.

4. Obstacles to Change. Drug policy is like prostitution policy; either legalization or a crackdown would likely improve on current policy. Weakly enforced prohibition increases specific risk without adequately reducing frequency.

From a libertarian viewpoint heroin addicts are victims of a bad policy. Cracking down on them seems wrong. Many police departments are almost equally unenthusiastic: street level drug enforcement is unpleasant work. As for making a special effort to shut down shooting galleries to protect heroin users from AIDS, the private comment of one New York City police

190. N.A.S., supra note 1, at 107 ("The further the distance from New York City, the lower the prevalence of seropositivity among IV drug users .... A [methadone maintenance treatment] program in a city approximately 100 miles from downtown New York had a seropositivity rate of 2 percent.").

191. "Works" are the equipment needed for intravenous drug use-a syringe and hypodermic needle. 
commander is straightforward: "As far as most cops are concerned, the faster all the junkies die, the better."'192

To the moralists and some consequentialists, on the other hand, legalization of heroin is a horrible idea. Their objections would not disappear even if they were convinced that the current misery and crime associated with heroin addiction are artifacts of prohibition. They would argue that the drug is pharmacologically, and independently of its legal status, a threat to the dignity and autonomy of its users. They would ask an important question: If we could slightly slow the spread of AIDS, but at the cost of adding to our several million alcoholics a similar or even larger number of legal heroin bums, would that be a good trade or bad one? The answer to that question remains unclear.

\section{F. Prisons}

Prisons combine a population likely to contain a high proportion of former IV drug users with an environment in which homosexual sex is fairly commonplace and in which IV drug use is not unknown. ${ }^{193}$ Each year, state prisons may be releasing hundreds men who have acquired HIV while in prison. ${ }^{194}$

Sex and drug use in prisons are already illegal, and reducing their frequency would require strengthening the enforcement of these prohibitions. Prison officials could increase surveillance of prisoners in situations where sexual activity or drug use is believed to be likely. In order to eradicate drug use, officials could also conduct frequent urine tests on prisoners and severely penalize those found to be using drugs. Many prison rapes go unreported because of fear of retribution. ${ }^{195}$ Tougher sanctions and improved reporting systems might reduce the incidence of forced sexual contact.

Reducing the specific risk of prison sex and drug use would be very difficult, although prisoners could benefit as much as anyone else from programs detailing the risks of certain sexual and other practices and explaining safer alternatives. The distribution of condoms in prisons would seem to sanction an illegal activity which prison officials blame for a substantial percentage of prison violence. ${ }^{196}$ Prison sex often serves both as a

192. Confidential interview with unnamed New York City police commander (Sept. 1986).

193. U.S. Department of Justice, Prisoners and Drugs, U.S. Bureau of Justice Statistics Bulletin, Mar. 1983, at 1 ( $30 \%$ of the prisoners sampled had used heroin at some time in their lives); $P$. Nacci \& T. Kane, Sex and Sexual Aggression in Federal Prisons 7 (Bureau of Prison Policy, unpublished report, 1982) (35-40\% of incarcerated males may have had a homosexual experience; $28 \%$ of federal inmates report homosexual experience); see also N.A.S., supra note 1, at 60 (citing U.S. Dep't of Justice, Prisoners and Drugs, supra).

194. M. Kleiman \& P. Mockler, supra note 138, at 16 (Kleiman and Mockler estimate 1800 per year.).

195. W. Wooden \& J. Parker, Men Behind Bars 106-07 (1982).

196. Cf. P. Nacci \& T. Kane, supra note 193, at 16 (Correctional officers believe that "consensual homosexuality in prison frequently leads to violence."). 
sexual outlet and as a form of aggression. ${ }^{197}$ Rape is at one pole of a continuum of sex/power relationships among prisoners. Because it is unlikely that rapists would use condoms, rape victims would remain vulnerable to disease. Distributing clean needles in prison would have all the problems of the same policy on the outside and some additional complications such as the potential uses of needles as weapons and an increased prison trade in drugs.

Reducing contacts between infected and uninfected prisoners would be rather simple in theory: Test all prisoners and segregate those who test positive. Such a policy would be vulnerable to lags in the development of antibodies, thus leaving some infected prisoners with the general population, and to false test results: A seronegative prisoner who tested positive would be placed in a highly dangerous environment, while seropositive prisoners left with the general population would constitute a risk to any partners in sex or needle sharing. Running a screening and segregation program would also pose serious problems of administration. In particular, staffing units which housed infected prisoners would be difficult.

Administrators would have to ensure that infected prisoners had facilities equal to those of the general prison population or risk violating the prisoners' rights of equal protection. ${ }^{198}$ Because repeated exposure to the virus may hasten the onset of disease in infected persons, units for segregated prisoners would also require especially diligent enforcement of anti-rape laws. Unless stringent anti-discrimination policies were in place, or unless prison officials could maintain the confidentiality of those released from HIV-positive units, infected prisoners who had been segregated could also face serious problems upon release. ${ }^{199}$

Uninfected prisoners have much to gain from screening and segregation programs, because these programs would substantially reduce their risk of contracting HIV. Indeed, the absence of such programs in prisons where rape is relatively common arguably subjects uninfected prisoners to cruel and unusual punishment. ${ }^{200}$ Screening and segregation would have some advantages over tougher enforcement of existing regulations; to be fully

197. Id. at 13 .

198. See also Vaid, Balanced Response Needed to AIDS in Prison, Nat'l Prison Proj. J., Spring 1986, at 1, 5. Cf. Vaid, NPP Gathers the Facts on AIDS in Prisons, NAT'L Prison Proj. J., Winter 1985, at 1, 3 (a claim of such violation would require a showing that plaintiffs were denied adequate food, clothing, shelter, sanitation, medical care, and safety).

199. Cf. Vaid, Balanced Response, supra note 198, at 1, 4 (There is little confidentiality of medical information in most prisons, and seropositive prisoners might be assaulted in the general population.).

200. T. Hammett, AIDS in Correctional Facilities: Issues and Options 15 (2d ed. 1987) [hereinafter Issues AND Options] (for the National Institute of Justice: Issues and Practices) (A Federal Bureau of Prisons Report indicates that between $9 \%$ and $20 \%$ of prison inmates ... are targets for aggressive sex acts during their incarceration (citing P. Nacci \& $T$. Kane, supra note 193, at 11.)). 
effective, such enforcement might require extreme invasions of privacy such as continual electronic surveillance. ${ }^{201}$

Yet there are few advocates for prison screening and segregation. Only a few states-and none of those with the highest estimated prisoner seroprevalence-even go so far as to test inmates, and the incidence of segregation has decreased in the last year. ${ }^{202}$ Most states do not even allow prisoners to request testing. ${ }^{203}$ Some moralists support such programs but generally have things other than the welfare of convicts to worry about. Libertarians are afraid of mandatory testing in any guise and generally support extensive education as the cure for the problem of transmission in prisons. ${ }^{204}$ Such educational programs have received fairly glowing reviews, ${ }^{205}$ but no one has yet done a serious study of whether or not they are effective in the prison setting.

Prison administrators consider liability suits on one side and administrative nightmares on the other, and they do not know what to do. Prison systems currently face lawsuits which both demand and oppose screening and segregation. ${ }^{206}$ The jury is still out on which policy is the safest in terms of liability.

With prisons, as with drug enforcement, prostitution, and day-to-day sexual encounters, little changes. The ongoing philosophical struggle between defenders of morality and defenders of liberty overpowers the defense of the public health.

\section{IV}

\section{Conclusion}

Having reviewed all of this information, it remains unclear, even from a purely consequentialist point of view, what will and will not help control the spread of HIV. Ignorance about a number of important factors-including the probability that an infected individual will progress to AIDS or ARC, the contact specific risks of different acts with respect to HIV transmission, the patterns of who does what with whom, and the dynamics of retransmission and how they vary across populations-makes decisionmaking harder.

201. But see generally J. Dilulio, Governing Prisons: A Comparative Study of Correctional MANAGEMENT (1987) (argument that better prison management focused on control can reduce prison rape and other misconduct).

202. T. Hammett, 1986 Update: AIDS in Correctional Facilities 10 (1987) [hereinafter UPDATE]. (Between November 1985 and October 1986, the percentage of city and county jail systems that segregated all three inmate categories-AIDS cases, ARC cases, and seropositivesdecreased from $41 \%$ to $27 \%$; the percentage of state and federal systems that segregate none of these categories increased from $4 \%$ to $12 \%$. The sample sizes for this survey were $\mathrm{n}=51$ for state and federal system, and $n=33$ for city and county systems; the October 1986 survey updated the status of the systems sampled in the November 1985 (original) survey.).

203. T. HammetT, Issues and Options, supra note 200 , at 39 (18\% of state/federal systems and $33 \%$ of city/county systems provide testing to any inmate upon request).

204. E.g., Vaid, NPP supra note 198, at 2; Bayer, supra note 52, at 1772.

205. See T. HAMmetT, Issues AND Options, supra note 200 , at 30.

206. Id. at xxiv-xxv. 
Technological barriers-to the treatment of AIDS and its prevention by vaccine, to eliminating false positive and false negative test results, to the design of legal systems to protect the rights of identified seropositivescomplicate matters. However, analysis demonstrates that some interventions are unambiguously helpful, while others, apparently innocuous at worst, could do more harm than good.

A simple model of the factors of risk points to three areas for intervention and behavioral change: frequency of risk contact, contact specific risks, and the proportion of risky acts involving a mix of seropositive and seronegative individuals. Any intervention faces two potentially serious complicationsrisk compensation and other unintended side effects.

Risk factors and the dynamics of retransmission vary across populations. While ignorance of the details of these differences hampers analysis to some degree, some conclusions remain robust. The first and most obvious of these is that different populations will have to take different actions to protect themselves from HIV, and that policy makers must account for these differences in designing interventions. A policy debate dominated, as the current national debate is, by the problems of high risk areas and groups may miss major opportunities. Spokane might benefit from approaches no longer relevant to New York.

It is also apparent that keeping HIV from spreading to new populations should have high priority, because of the large number of retransmissions likely to stem from new infections in populations with relatively low current seroprevalence. At the same time, analysis shows that members of "risk groups" face grave risks of infection over their lifetimes. Such risks may necessitate both massive behavioral changes and such extraordinary measures as the creation of serum status identification systems to protect the uninfected and to provide sexual opportunity to the infected. High risks may also justify extraordinary efforts to discourage people from becoming members of risk groups.

Ideally, analysis would also help in allocating limited resources within and across populations. To a certain extent it does this now by pointing to "firebreaks" such as existing barriers between populations and by demonstrating the risk factors which are possible to change within groups. However, public agencies do not work from a single pool of resources. This both reduces the efficiency with which resources can be targeted and reduces the number of hard choices (for example, between reducing transmissions among IV drug users and reducing them among transfusion recipients) which must be faced, since avenues and agencies exist to confront many of the different "margins" of the epidemic simultaneously.

Policy analysis, then, has something to say about the AIDS epidemic and how to limit it. It can allow at least rough calculations of efficacy and rough comparisons of cost effectiveness across the choices to be made given current knowledge and technique. By illuminating crucial areas of ignorance, it can 
guide future research efforts. Finally, analysis shows that people who say that the AIDS problem will be solved by "education" are either using the term extremely broadly or are badly oversimplifying the AIDS problem. 